\title{
Methylobacterium extorquens: methylotrophy and biotechnological applications
}

\author{
Andrea M. Ochsner - Frank Sonntag - Markus Buchhaupt • \\ Jens Schrader • Julia A. Vorholt
}

Received: 17 September 2014 / Revised: 14 November 2014 / Accepted: 16 November 2014 / Published online: 30 November 2014

(C) Springer-Verlag Berlin Heidelberg 2014

\begin{abstract}
Methylotrophy is the ability to use reduced onecarbon compounds, such as methanol, as a single source of carbon and energy. Methanol is, due to its availability and potential for production from renewable resources, a valuable feedstock for biotechnology. Nature offers a variety of methylotrophic microorganisms that differ in their metabolism and represent resources for engineering of value-added products from methanol. The most extensively studied methylotroph is the Alphaproteobacterium Methylobacterium extorquens. Over the past five decades, the metabolism of M. extorquens has been investigated physiologically, biochemically, and more recently, using complementary omics technologies such as transcriptomics, proteomics, metabolomics, and fluxomics. These approaches, together with a genome-scale metabolic model, facilitate system-wide studies and the development of rational strategies for the successful generation of desired products from methanol. This review summarizes the knowledge of methylotrophy in M. extorquens, as well as the available tools and biotechnological applications.
\end{abstract}

Keywords Methylobacterium extorquens · Methanol · Methylotrophy $\cdot$ Industrial biotechnology

Andrea M. Ochsner and Frank Sonntag contributed equally to the manuscript.

Electronic supplementary material The online version of this article (doi:10.1007/s00253-014-6240-3) contains supplementary material, which is available to authorized users.

A. M. Ochsner · J. A. Vorholt $(\bowtie)$ Institute of Microbiology, ETH Zurich, Vladimir-Prelog-Weg 4, 8093 Zurich, Switzerland

e-mail: julia.vorholt@micro.biol.ethz.ch

F. Sonntag $\cdot$ M. Buchhaupt $\cdot$ J. Schrader

DECHEMA Forschungsinstitut, Theodor-Heuss-Allee 25,

60486 Frankfurt am Main, Germany

\section{Introduction}

Methylobacterium is a widespread genus that can be readily isolated from various habitats including wastewater (Kohler-Staub et al. 1986), soil (Doronina and Trotsenko 1996), and the phyllosphere where they are present in large numbers (Delmotte et al. 2009; Vorholt 2012). Its ability to use plant-derived methanol as an energy substrate provides an advantage during plant colonization under competitive conditions (Abanda-Nkpwatt et al. 2006; Fall and Benson 1996; Sy et al. 2005). One of the most intensively studied species of the genus is Methylobacterium extorquens and in particular strain AM1 which has been investigated as a model organism for methylotrophy for more than 50 years (Anthony 2011). Detailed information on the methylotrophic metabolism has been uncovered from core enzyme functions to pathways up to a genome-scale metabolic model. In addition, omics approaches have helped to describe methylotrophy on a systems level. The latter approaches initially became possible through the determination of the genome of M. extorquens AM1, for which a fully annotated genome sequence is available, as well as a genome-scale metabolic model. Furthermore, a versatile set of genetic tools has been developed and applied for gene deletions and overexpression, as well as random mutagenesis and chromosomal gene integration. Finally, bioprocess engineering led to the development of high cell density fermentation protocols for several $M$. extorquens strains (see below).

The accumulated knowledge about the biology and technical use of $M$. extorquens together with the availability of genetic tools has led to a constant increase in interest in the use of this methylotroph as a microbial host for the production of valueadded compounds. Accretive industrialization and growing world population encourage the discussion about alternative raw materials to become more independent of steadily 
increasing oil prices but also to avoid direct competition with resources used for food production (Schrader et al. 2009).

Methanol is already an important carbon feedstock for the chemical industry with a worldwide production of approximately 53 million tons in 2011 and an expected annual growth rate in the range of 10-20\% (Bertau et al. 2014), and a methanol-based bioeconomy has been proposed (Olah 2013). In addition to its worldwide availability, methanol production is flexible. The majority of today's methanol is produced from fossil raw materials, such as crude oil, coal, and natural gas, but in the future an increasing share is expected to be produced from renewables or sustainable sources, such as biogas, glycerol, wood, or solid municipal waste (Schrader et al. 2009). For example, a biomass-to-methanol (BtM) plant (that produces methanol starting from forest residues) with a capacity of $100,000 \mathrm{t} / \mathrm{a}$ is currently being projected in Sweden (Bertau et al. 2014). Such endeavors illustrate that methanol is producible in various ways, and consequently, industrial biotechnology based on this compound is less dependent on market price fluctuations of raw materials. However, compared to sugars, the market price of which is approximately $0.2 \$ / \mathrm{kg}$ (Peralta-Yahya et al. 2012) corresponding to $0.5 \$$ per kilogram substrate carbon, methanol is still more expensive with a price of approximately $0.45 \$ / \mathrm{kg}$ (Bertau et al. 2014), corresponding to approximately $1.2 \$$ per kilogram substrate carbon. On the other hand, sugar is an agricultural commodity, which is subject to strict price regulations and import limitations in Europe. This impairs free-market conditions which apply for any intermediate in the chemical industry, including methanol. As the price for sugar derived from arable land - the common fermentation substrate in industrial biotechnology - is expected to steadily increase due to its linkage to the food sector, and sugar from lignocellulosics still suffers from severe technical challenges, "bio-methanol" will become an attractive alternative for the establishment of sustainable bioprocesses in the future (Schrader et al. 2009).

Within this review, we summarize the current knowledge of methylotrophy in Methylobacterium and its use for methanol conversion to value-added products. Additional applied aspects of Methylobacterium strains, such as plant growthpromoting microbials in agriculture (Fedorov et al. 2011; Joe et al. 2013; Tani et al. 2012), are beyond the scope of this review. For a recent review on a thermophilic methylotroph, Bacillus methanolicus, the reader is referred to Müller et al. (2014).

\section{Model strains of M. extorquens, growth substrates and genomes}

The first model methylotrophic bacterium and the most extensively studied to date is $M$. extorquens AM1. It was initially called Pseudomonas AM1 and was isolated in Oxford as an airborne contaminant in methylamine medium (Peel and Quayle 1961), hence the name AM1 for airborne methylamine. It grows on the reduced $\mathrm{C} 1$ substrates methanol and methylamine but also as a facultative methylotroph on multicarbon substrates such as succinate (C4) and acetate (C2) (Large et al. 1961; Schneider et al. 2012a) (for a more detailed list, see Table S1). The genome sequence of $M$. extorquens AM1 revealed a $6.88-\mathrm{Mb}$ genome consisting of a chromosome, a megaplasmid, and three smaller plasmids (Vuilleumier et al. 2009). An additional number of Methylobacterium strains have been sequenced (Marx et al. 2012; Vuilleumier et al. 2009) (Table 1) including M. extorquens PA1 that was recently selected as a competitive colonizer of the phyllosphere of Arabidopsis thaliana (Knief et al. 2010) (PA1 for phyllosphere of Arabidopsis). Further $M$. extorquens strains that have been characterized and sequenced include strains that are able to grow on chloromethane (strain CM4) and dichloromethane (strain DM4). All of the strains harbor a genome of 5.4-5.9 Mb and one or two plasmids (except strain PA1 which has none); as mentioned above, strain AM1 also contains a megaplasmid. While the function of the plasmids of $M$. extorquens AM1, DM4, and BJ001 is unknown, the $380-\mathrm{kb}$ plasmid of strain CM4 was shown to carry genes for chloromethane dehalogenation (Roselli et al. 2013).

This review will mainly focus on the model strain M. extorquens AM1 and occasionally refer to strain PA1, which in our opinion represents a valuable alternative to $M$. extorquens AM1 for further research on methylotrophy. This is due to the simpler genome structure, the applicability of genetic screens (Metzger et al. 2013), and the overall conserved methylotrophy features compared to the AM1 strain (Nayak and Marx 2014b). In addition, strain PA1 lacks the long history of domestication, which led to divergence from the initially isolated strain (Carroll et al. 2014).

\section{Tools developed and applied for M. extorquens}

Genetic tools have been used since the early research of $M$. extorquens AM1 to identify essential genes for methylotrophy. Historically, chemical mutagenesis was applied (Heptinstall and Quayle 1970) in combination with complementation analysis to classify mutants into different complementation groups (Nunn and Lidstrom 1986). Subsequently, site-directed knockouts (Chistoserdova and Lidstrom 1992) and transposon mutagenesis (Springer et al. 1995) were established. To date, a broad selection of genetic tools for expression, knockout, and transposon mutagenesis, has been described (Table 2), and the genetic toolbox for M. extorquens and other Alphaproteobacteria is constantly 
Table 1 List of genome sequenced $M$. extorquens strains

\begin{tabular}{|c|c|c|c|}
\hline Strain & Isolation & C1 substrates & Genome \\
\hline AM1 & $\begin{array}{l}\text { Airborne contaminant in methylamine } \\
\text { (Peel and Quayle 1961) }\end{array}$ & Methanol, methylamine & $\begin{array}{l}\text { Chromosome: } 5.511 \mathrm{Mb} \\
\text { Megaplasmid: } 1.26 \mathrm{Mb} \\
\text { Plasmids: } 44 \mathrm{~kb}, 38 \mathrm{~kb}, 25 \mathrm{~kb} \\
\text { (Vuilleumier et al. 2009) }\end{array}$ \\
\hline $\mathrm{DM} 4^{\mathrm{a}}$ & $\begin{array}{l}\text { Soil from a treatment plant for halogenated } \\
\text { hydrocarbon waste } \\
\text { (Kohler-Staub et al. 1986) }\end{array}$ & $\begin{array}{l}\text { Methanol, dichloromethane } \\
\text { (Kohler-Staub et al. 1986) }\end{array}$ & $\begin{array}{l}\text { Chromosome: } 5.94 \mathrm{Mb} \\
\text { Plasmids: } 140 \mathrm{~kb}, 39 \mathrm{~kb} \\
\text { (Vuilleumier et al. 2009) }\end{array}$ \\
\hline PA1 & $\begin{array}{l}\text { Arabidopsis thaliana phyllosphere } \\
\text { (Knief et al. 2010) }\end{array}$ & $\begin{array}{l}\text { Methanol, methylamine } \\
\text { (Knief et al. 2010) }\end{array}$ & Chromosome: $5.471 \mathrm{Mb}$ (Marx et al. 2012) \\
\hline $\mathrm{CM} 4^{\mathrm{b}}$ & $\begin{array}{l}\text { Soil of petrochemical factory } \\
\quad \text { (Doronina and Trotsenko 1996) }\end{array}$ & $\begin{array}{l}\text { Methanol, methylamine, chloromethane } \\
\text { (Doronina and Trotsenko 1996) }\end{array}$ & $\begin{array}{l}\text { Chromosome: } 5.778 \mathrm{Mb} \\
\text { Plasmids: } 380 \mathrm{~kb}, 23 \mathrm{~kb} \text { (Marx et al. 2012) }\end{array}$ \\
\hline BJ001 ${ }^{\mathrm{c}}$ & $\begin{array}{l}\text { Populus deltoides } \times \text { nigra } \text { DN34 endophyte } \\
\quad \text { (Van Aken et al. 2004) }\end{array}$ & $\begin{array}{l}\text { Methanol, methane }{ }^{\mathrm{d}} \text { methylamine } \\
\text { (Van Aken et al. 2004) }\end{array}$ & $\begin{array}{l}\text { Chromosome: } 5.8 \mathrm{Mb} \\
\text { plasmids: } 25 \mathrm{~kb}, 23 \mathrm{~kb} \\
\text { (Marx et al. 2012) }\end{array}$ \\
\hline
\end{tabular}

${ }^{\text {a }}$ Previously Methylobacterium dichloromethanicum DM4

${ }^{\mathrm{b}}$ Previously Methylobacterium chloromethanicum CM4

${ }^{\mathrm{c}}$ Previously Methylobacterium populi BJ001

${ }^{\mathrm{d}}$ Was disputed (Dedysh et al. 2004); genome sequencing later revealed the lack of characteristic genes for methane monooxygenase ( $p m o A B C$ and mmoXYBZDC)

expanding. Moreover, a recent study provided a modified cellulose synthase, optimized for reproducible highmedium and a genetically engineered strain, which lacks throughput growth experiments (Delaney et al. 2013).

Table 2 List of available genetic tools for M. extorquens AM1

\begin{tabular}{|c|c|c|}
\hline Genetic tools & Description & Reference \\
\hline \multicolumn{3}{|l|}{ Expression systems } \\
\hline \multicolumn{3}{|l|}{ Plasmid-borne } \\
\hline \multicolumn{3}{|l|}{ Constitutive } \\
\hline $\mathrm{P}_{\mathrm{mxaF}} / \mathrm{P}_{\mathrm{lac}}$ & $\begin{array}{l}\text { pCM80 (TetR), pCM160 (KanR) IncP } \\
\text { oriV, oriT }(\mathrm{RK} 2 \text {-derived) }\end{array}$ & Marx and Lidstrom (2001) \\
\hline Methylobricks $\left(\mathrm{P}_{\mathrm{mxaF}}\right), \mathrm{P}_{\text {fumC }}, \mathrm{P}_{\mathrm{coxB}}, \mathrm{P}_{\text {tuf }}$ & $\begin{array}{l}\text { Derived from promoter-less pCM80 } \\
\text { (TetR) (also KanR available) }\end{array}$ & $\begin{array}{l}\text { Schada von } \\
\quad \text { Borzyskowski et al. (2014) }\end{array}$ \\
\hline \multicolumn{3}{|l|}{ Inducible } \\
\hline Cumate-inducible $\mathrm{P}_{\mathrm{mxaF}}$ & Regulator cymR chromosomally integrated & Choi et al. (2006) \\
\hline Cumate-inducible $\mathrm{P}_{\mathrm{mxaF}}$ & $\begin{array}{l}\text { pHC115, cymR encoded on plasmid, comparatively } \\
\text { high background expression }\end{array}$ & Chou and Marx (2012) \\
\hline Cumate/anhydrotetracycline-inducible $\mathrm{P}_{\mathrm{R}}$ & pLC290, pLC291 (both KanR) & Chubiz et al. (2013) \\
\hline Cumate-inducible $\mathrm{P}_{\mathrm{syn} 2}$ & pQ2148, tight promoter & Kaczmarczyk et al. (2013) \\
\hline \multicolumn{3}{|l|}{ Insertional } \\
\hline pCM168/pCM172 & $\begin{array}{l}\text { Chromosomal insertion of desired gene into } \\
\text { katA gene loxP-flanked resistance marker }\end{array}$ & Marx and Lidstrom (2004) \\
\hline \multicolumn{3}{|l|}{ Transposons used for genetic screens } \\
\hline pCM639 & Mini Tn-5 derivative IsphoA/hah-Tc & Marx et al. (2003c) \\
\hline pAlmar3 & Mariner transposon (used in strain PA1) & Metzger et al. (2013) \\
\hline \multicolumn{3}{|l|}{ Site-directed knockout } \\
\hline pAYC61 & & Chistoserdov et al. (1994) \\
\hline pCM184 & Cre-lox-based system allows unmarked deletions & Marx and Lidstrom (2002) \\
\hline pCM433 & SacB-based bhr vector & Marx (2008) \\
\hline
\end{tabular}


The fact that $M$. extorquens is a facultative methylotroph represents a useful trait to study methylotrophy. Knockout mutants in essential genes for methylotrophy can be generated on an alternative carbon source and then selected on methanol, thus facilitating the discrimination between true essential genes for methylotrophy and potential technical obstacles to generate a particular gene knockout.

Much of the knowledge generated for M. extorquens AM1 is based on classical biochemical studies resulting from enzyme discovery to gene discovery or vice versa. More recently, a number of complementary omics approaches have been applied including transcriptomics, proteomics, and metabolomics to characterize methylotrophy more systematically (Table 3 ). In these studies, cell analytes detected under methylotrophic conditions were compared to those detected under nonmethylotrophic growth conditions, usually succinate, which results in similar growth rates (Peyraud et al. 2012). These studies gave valuable insights into methylotrophic metabolism and represent useful tools for further studies. Comparative proteomics and a microarray study revealed proteins/ transcripts that were differentially expressed under methylotrophic conditions compared to non-methylotrophic conditions (Bosch et al. 2008; Laukel et al. 2004; Okubo et al. 2007). These experiments demonstrated the induction of proteins/transcripts known to be involved in methylotrophy, as well as many with unknown functions.

Different methods to study the metabolome have been applied to $M$. extorquens. These methods include nucleotide determination (including ATP and NAD) (Guo and Lidstrom 2006), metabolite profiling (Guo and Lidstrom 2008), and quantitative metabolome analyses (Kiefer et al. 2011; Kiefer et al. 2008). In addition, a method to quantify CoA-esters has been established and was employed to demonstrate the ethylmalonyl-CoA pathway (EMCP) in M. extorquens AM1 (Peyraud et al. 2009).

Recently, a genome-scale model of the methylotrophic metabolism of $M$. extorquens was established by integrating all available information including omics, biochemical, and mutation studies (Peyraud et al. 2011). The functionality of the metabolic network was analyzed in silico including elementary flux mode analysis, and the model was tested for network topology and features. In addition, methylotrophy was examined experimentally using ${ }^{13} \mathrm{C}$-fluxomics via NMR and mass spectrometry (Peyraud et al. 2011). The study provided valuable information about the different pathways utilized during methylotrophic growth and demonstrated the presence of a degree of connectivity of the core metabolism as a mosaic of common and specific pathways. It was also proposed that methylotrophy is under constant selection in nature, which is in line with experimental evolution experiments, where prolonged selection on succinate resulted in a loss of the ability to grow on $\mathrm{C} 1$ compounds in a part of the population (Lee et al. 2009).

\section{Methylotrophy in M. extorquens}

Methylotrophy can be divided into different parts, which altogether allow metabolization of the reduced $\mathrm{C} 1$ carbon source for energetic and biosynthetic purposes: (1) oxidation of primary $\mathrm{C} 1$ substrate to formaldehyde, (2) oxidation of formaldehyde to $\mathrm{CO}_{2}$, and (3) assimilation into biomass (Chistoserdova 2011). Different combinations of enzymes and pathways exist, which represent "solutions" found in nature. In the following section, the crucial steps of methylotrophy in $M$. extorquens AM1 are described after a short historical perspective. A graphical overview of methylotrophy in $M$. extorquens AM1 is shown in Fig. 1 and a list of the involved genes including information on their essentiality and regulation is given in Table S2.

\section{M. extorquens AM1 as a model organism for enzyme and pathway discovery}

As mentioned above, M. extorquens AM1 has been an important model organism for methylotrophy in the past half century. In fact, many enzymes and pathways relevant for $\mathrm{C} 1$ metabolism in more general terms have been discovered in this bacterium and are now known to be widespread among methylotrophs (Chistoserdova 2011).

The serine cycle for $\mathrm{C} 1$ assimilation was elucidated in M. extorquens AM1 already more than five decades ago through the seminal work of Quayle and colleagues (Large et al. 1961, 1962a, b; Large and Quayle 1963). The continuous operation of this pathway requires the regeneration of glyoxylate. Interestingly, $M$. extorquens lacks isocitrate lyase (Dunstan and Anthony 1973), the key enzyme of the known glyoxylate cycle (Kornberg and Krebs 1957), and uses an alternative route for glyoxylate regeneration. The exact sequence of reactions of this pathway, termed the EMCP, was only solved a few years ago (Erb et al. 2007; Peyraud et al. 2009). For a historic overview of the elucidation of the serine cycle and the EMCP, we refer to the recent review by Anthony (2011).

Another important discovery was that the catabolic formaldehyde oxidation in $M$. extorquens AM1 depends on tetrahydromethanopterin $\left(\mathrm{H}_{4} \mathrm{MPT}\right)$, which was previously believed to be unique to methanogenic and sulfate-reducing Archaea (Chistoserdova et al. 1998). In M. extorquens, the $\mathrm{H}_{4}$ MPT-dependent pathway functions in the reverse direction compared to the known mode of operation in hydrogenotrophic methanogens and catalyzes the oxidation of formaldehyde to formate. The pathways described above were subsequently discovered in other microorganisms capable of growth on $\mathrm{C} 1$ compounds, including aerobic proteobacterial methanotrophs (Chistoserdova et al. 2005b; Vorholt et al. 1999) as well as an anaerobic bacterial methanotroph (Ettwig et al. 2010). 
Table 3 Overview of omics studies investigating methylotrophy in M. extorquens AM1

\begin{tabular}{|c|c|c|}
\hline Omics study & Reference & Description \\
\hline Genome & Vuilleumier et al. (2009) & \\
\hline Genome scale model & Peyraud et al. (2011) & \\
\hline Proteomics & Laukel et al. (2004), Bosch et al. (2008) & $\begin{array}{l}\text { Comparison of methanol and succinate: gel-based approach (2004) and } \\
\text { multidimensional protein identifications technology } \\
\text { (MudPIT) (2008) }\end{array}$ \\
\hline Transcriptomics & Okubo et al. (2007) & Comparison of methanol and succinate microarray \\
\hline \multicolumn{3}{|l|}{ Metabolomics } \\
\hline Metabolite profiling & Guo and Lidstrom (2008) & Metabolite profiles during growth on methanol and succinate \\
\hline $\begin{array}{l}\text { Quantitative metabolome } \\
\text { analysis }\end{array}$ & Kiefer et al. (2011); Kiefer et al. (2008) & Concentration of central metabolites on methanol and succinate \\
\hline CoA-esters determination & Peyraud et al. (2009) & $\begin{array}{l}\text { Quantification and dynamic labeling of CoA-esters during } \\
\text { methylotrophic growth }\end{array}$ \\
\hline${ }^{13}$ C-Fluxomics & Peyraud et al. (2011) & Investigation of metabolic fluxes during methylotrophic growth \\
\hline Metabolite discovery & (Yang et al. 2013) & $\begin{array}{l}\text { Determination of metabolites labeled during growth } \\
\text { on }{ }^{13} \mathrm{C} \text {-labeled methanol }\end{array}$ \\
\hline
\end{tabular}

\section{Methanol oxidation}

In $M$. extorquens, methanol oxidation is catalyzed by a periplasmatic pyrroloquinoline quinone (PQQ)-dependent methanol dehydrogenase (MDH) (Anthony 1986). MDH has a hetero-tetrameric $\alpha_{2} \beta_{2}$ structure where each $\alpha$-subunit contains one $\mathrm{Ca}^{2+}$ ion and one PQQ as a prosthetic group (reviewed in Anthony and Williams 2003). The large (66 $\mathrm{kDa}) \alpha$-subunit is encoded by mxaF and the small
$(9 \mathrm{kDa}) \beta$-subunit by mxal. The electrons taken up by the MDH-bound PQQ during the oxidation of methanol are transferred to the unique cytochrome $c_{L}(m x a G)$, then further via the type I cytochrome $c_{H}$ to cytochrome $c$ oxidase and eventually to oxygen (Anthony 1992). These genes are located in a gene cluster together with genes thought to have auxiliary functions (Morris et al. 1995; Richardson and Anthony 1992). The genes for the biosynthesis of the cofactor PQQ $(p q q A B C / D E, p q q F G)$ are located in two clusters elsewhere in

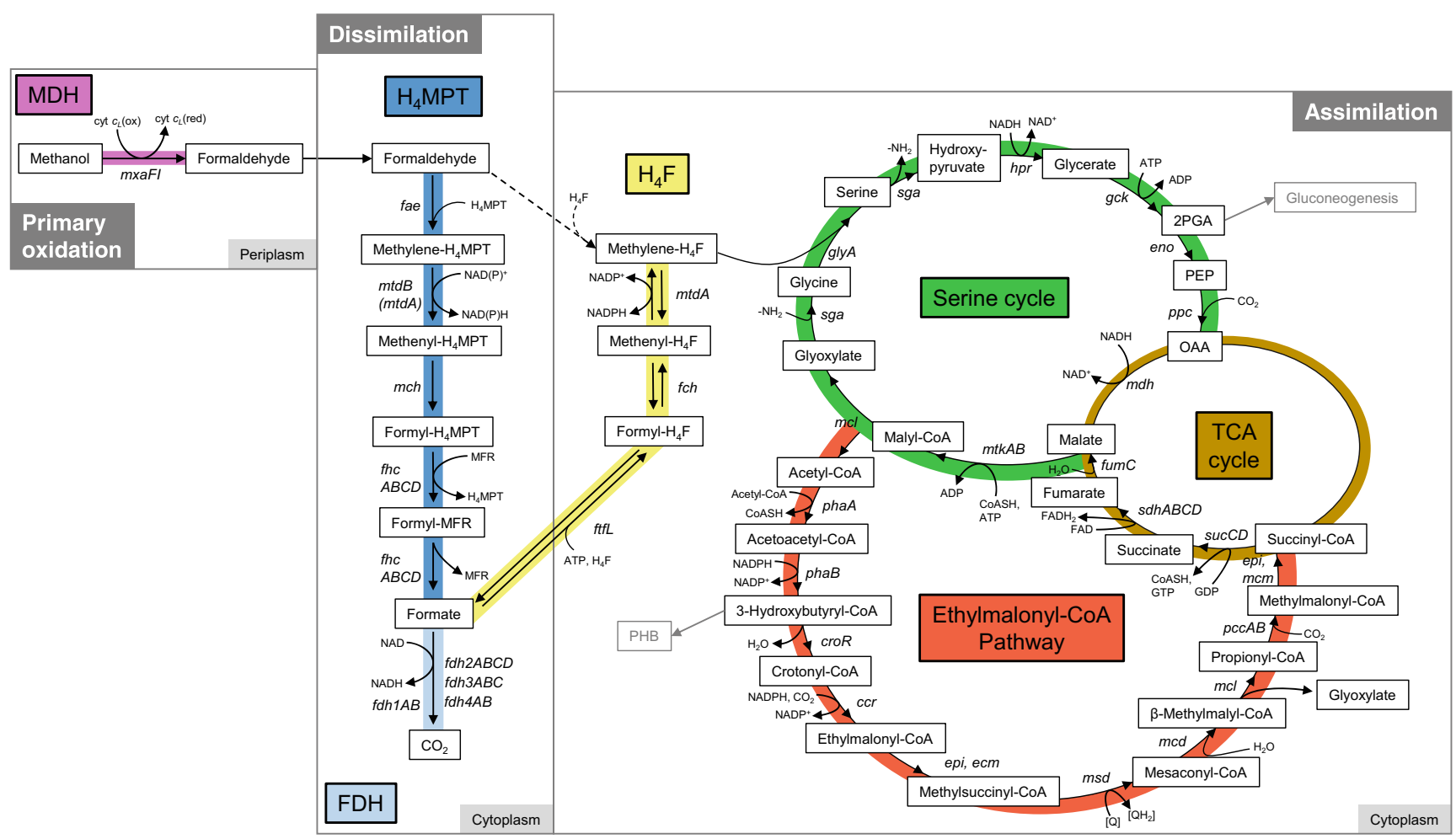

Fig. 1 Overview of methanol metabolism in M. extorquens AM1. The coloring marks the different pathways. Genes encoding for the corresponding enzymes are shown in italics. For a detailed list of the involved genes, refer to Table S2 
the genome (Chistoserdova et al. 2003; Morris et al. 1994; Toyama et al. 1997).

The genome sequence of $M$. extorquens AM1 revealed the presence of several gene-encoding paralogs of the large subunit of methanol dehydrogenase, such as $x o x F 1$ (Chistoserdova and Lidstrom 1997), which has a sequence identity of approximately $50 \%$. The enzyme has methanol and formaldehyde oxidation activity (Schmidt et al. 2010) and is able to replace MxaF as a $\mathrm{La}^{3+}$-dependent methanol dehydrogenases under distinct conditions (Nakagawa et al. 2012). In addition to its catalytic role, $x o x F 1$ is, together with its paralog $x o x F 2$, postulated to be involved in regulation (Skovran et al. 2011). Interestingly, xoxF is highly expressed in the phyllosphere (Delmotte et al. 2009) and plays a role in plant colonization (Schmidt et al. 2010).

Formaldehyde dissimilation

Formaldehyde produced by methanol dehydrogenase in M. extorquens AM1 is further oxidized by a $\mathrm{H}_{4} \mathrm{MPT}$-dependent pathway (Chistoserdova et al. 1998) which, in addition to its catabolic role, can also participate in formaldehyde detoxification (Marx et al. 2003a) (Fig. 1). M. extorquens AM1 produces a dephosphorylated form of $\mathrm{H}_{4}$ MPT lacking the terminal $\alpha$ hydroxyglutaryl phosphate unit $\left(\mathrm{dH}_{4} \mathrm{MPT}\right)$ (Chistoserdova et al. 1998). Several genes involved in the biosynthesis of $\mathrm{dH}_{4} \mathrm{MPT}$ in methylotrophs have been identified (Chistoserdova et al. 2005a) and the gene products of two of them, $m p t G$ (Rasche et al. 2004) and $d m r A$ (Caccamo et al. 2004; Marx et al. 2003c)), have been characterized.

The first step in formaldehyde conversion consists of the condensation of formaldehyde with $\mathrm{dH}_{4} \mathrm{MPT}$ to methylene$\mathrm{dH}_{4} \mathrm{MPT}$, a step which occurs spontaneously (EscalanteSemerena et al. 1984). Nevertheless, an enzyme accelerating the condensation of formaldehyde with $\mathrm{dH}_{4} \mathrm{MPT}$, termed formaldehyde-activating enzyme (Fae), could be identified in M. extorquens AM1 and is essential for methylotrophy (Acharya et al. 2005; Vorholt et al. 2000). Fae is produced in high amounts under both methylotrophic and nonmethylotrophic conditions, whereby the presence of the enzyme on methanol is slightly higher (Bosch et al. 2008). Mutants of the fae gene are sensitive to formaldehyde, suggesting that the spontaneous reaction is not efficient enough to detoxify formaldehyde (Vorholt et al. 2000).

The formed methylene- $\mathrm{dH}_{4} \mathrm{MPT}$ is oxidized to methenyl$\mathrm{dH}_{4} \mathrm{MPT}$ by methylene- $\mathrm{H}_{4} \mathrm{MPT}$ dehydrogenases MtdA and $\mathrm{MtdB}$, which in contrast to their $\mathrm{F}_{420}$-dependent archaeal counterparts (Thauer 1998) represent unique enzymes because they use pyridine nucleotides (NAD and NADP) (Vorholt et al. 1998). The NADP-specific MtdA catalyzes the reaction for methylene-tetrahydrofolate $\left(\mathrm{H}_{4} \mathrm{~F}\right)$ as well as methylene- $\mathrm{H}_{4}$ MPT (Ermler et al. 2002; Hagemeier et al. 2000; Vorholt et al. 1998), while the NAD(P)-dependent $\mathrm{MtdB}$ is specific for methylene- $\mathrm{dH}_{4} \mathrm{MPT}$ (Hagemeier et al.
2000). They both are essential under methylotrophic growth conditions and play distinct roles in controlling the flux of $\mathrm{C} 1$ units (Martinez-Gomez et al. 2013; Marx and Lidstrom 2004).

Methenyl- $\mathrm{dH}_{4} \mathrm{MPT}$ is converted to $N^{5}$-formyl- $\mathrm{dH}_{4} \mathrm{MPT}$ by methenyl- $\mathrm{dH}_{4} \mathrm{MPT}$ cyclohydrolase (Mch) (Pomper et al. 1999). The formyl group is then transferred to methanofuran (MFR) by formyltransferase (Ftr). The Ftr-homolog of AM1 (FhcD) forms a complex with three polypeptides that possess sequence identity to formyl-MFR dehydrogenase (FhcABC) (Pomper and Vorholt 2001). Contrary to initial expectations deduced from the analogous enzymatic steps in methanogenic archaea (Vorholt and Thauer 2002), this complex did not catalyze the oxidation of formyl-MFR but instead catalyzed the hydrolysis to formate. The complex was therefore renamed formyltransferase/hydrolase complex (Fhc) (Pomper et al. 2002).

The final oxidation step from formate to $\mathrm{CO}_{2}$ is catalyzed by several formate dehydrogenases $(\mathrm{Fdh})$, of which only one has been biochemically characterized thus far (Laukel et al. 2003). Subsequently, three more formate dehydrogenases were discovered (Chistoserdova et al. 2007; Chistoserdova et al. 2004). A triple mutant was still able to grow on methanol, but accumulated formate, whereas a quadruple mutant was unable to grow on methanol, which indicates that formate oxidation is essential for growth on methanol (Chistoserdova et al. 2007) and points towards an important role of formate as an intermediate with tightly regulated fluxes and/or yet undiscovered regulatory processes.

\section{Assimilatory pathways}

The serine cycle for the assimilation of $\mathrm{C} 1$ substrates was first shown in M. extorquens AM1 (Large et al. 1961, 1962a, b; Large and Quayle 1963). The $\mathrm{C} 1$ unit enters the serine cycle via condensation of methylene- $\mathrm{H}_{4} \mathrm{~F}$ (see below) with glycine to serine catalyzed by serine hydroxymethyltransferase (GlyA). GlyA is also present in most non-methylotrophic organisms where it provides methylene- $\mathrm{H}_{4} \mathrm{~F}$ for biosynthesis (Maden 2000). The produced serine is transformed to glyoxylate (to regenerate glycine) and acetyl-CoA. The pathway occurs via intermediates partly shared with gluconeogenesis and the tricarboxylic acid (TCA) cycle and involves a $\mathrm{CO}_{2}$ fixation step (Anthony 1982) (Fig. 1). None of the genes of the serine cycle are specific for methylotrophic metabolism, but a characteristic feature for methylotrophs is the clustering of the involved genes on the genome (Chistoserdova 2011). In M. extorquens AM1, most serine cycle genes are present in one cluster and are transcribed in two operons (Chistoserdova et al. 2003).

The C1-donor methylene- $\mathrm{H}_{4} \mathrm{~F}$ for the conversion of glycine to serine can principally be produced in two ways: via a direct and indirect route. The direct pathway involves the spontaneous condensation of formaldehyde with $\mathrm{H}_{4} \mathrm{~F}$ to methylene- $\mathrm{H}_{4} \mathrm{~F}$, whereas the indirect route involves the oxidation 
of formaldehyde to formate via the $\mathrm{H}_{4} \mathrm{MPT}$-dependent pathway followed by ATP-dependent condensation with $\mathrm{H}_{4} \mathrm{~F}$ catalyzed by formate tetrahydrofolate ligase (FtfL) (Marx et al. $2003 \mathrm{~b}$ ). The produced formyl- $\mathrm{H}_{4} \mathrm{~F}$ is converted to methenyl$\mathrm{H}_{4} \mathrm{~F}$ (catalyzed by Fch), and subsequently to methylene- $\mathrm{H}_{4} \mathrm{~F}$ catalyzed by the bifunctional NADP(P)-dependent MtdA enzyme (Vorholt et al. 1998). Experimental data on the operation of the $\mathrm{H}_{4} \mathrm{~F}$-dependent pathway in situ is controversial. An earlier study suggested a direct condensation of formaldehyde with $\mathrm{H}_{4} \mathrm{~F}$ and an indirect route only during a substrate switch (Marx et al. 2005); however, a more recent paper provides evidence for the condensation of formate with $\mathrm{H}_{4} \mathrm{~F}$ followed by reduction being more important than the direct condensation of formaldehyde with $\mathrm{H}_{4} \mathrm{~F}$ (Crowther et al. 2008). Future studies using dynamic ${ }^{13} \mathrm{C}$ labeling from methanol will be required to directly demonstrate the carbon flow via cofactorbound $\mathrm{C} 1$ intermediates.

Because metabolic intermediates are withdrawn from the serine cycle, glyoxylate must be regenerated to keep the pathway running. $M$. extorquens AM1 does not use the classical pathway involving isocitrate lyase but instead uses a series of CoA intermediates (Korotkova et al. 2002a; Korotkova et al. 2005). Based on the discovery of the carboxylation activity of crotonyl-CoA reductase (Ccr) (renamed crotonyl-CoA carboxylase/reductase), the EMCP was proposed and shown to operate in $M$. extorquens (Alber et al. 2006; Erb et al. 2007; Meister et al. 2005; Peyraud et al. 2009). The first step of the pathway is the condensation of two acetylCoA units, which are then transformed into methylmalyl-CoA over a series of $\mathrm{CoA}$ thioester derivatives involving a $\mathrm{CO}_{2}$ fixation step. Methylmalyl-CoA is cleaved to glyoxylate and propionyl-CoA, which can be converted to $\mathrm{C} 4$ compounds, such as succinate, via another carboxylation reaction. This pathway shares many enzymes with other pathways, but unlike the serine cycle, it also possesses unique reactions. Two of these are ethylmalonyl-CoA mutase (Ecm) (Erb et al. 2008) and the above-mentioned crotonylCoA reductase/carboxylase (Ccr) (Erb et al. 2007). Unlike other methylotrophy genes, the genes of the EMCP are not localized in large operons but are loosely clustered or not colocalized at all (Hu and Lidstrom 2012).

\section{Alternative $\mathrm{C} 1$ carbon sources}

Different $M$. extorquens strains grow on a number of additional C1 compounds, including methylamine, chloromethane, and dichloromethane (Chistoserdova and Lidstrom 2013). For all these different substrates, specific metabolic pathways can be identified (Chistoserdova 2011). Methylamine is oxidized to formaldehyde by a tryptophan tryptophylquinone (TTQ)-dependent methylamine dehydrogenase (encoded by mau cluster in strain AM1) with amicyanin as the electron acceptor (Chistoserdov et al.
1994). Strains PA1 and DM4, which both lack the mau cluster, were recently shown to use the $N$-methylglutamate pathway for growth on methylamine (Gruffaz et al. 2014; Nayak and Marx 2014b). Chloromethane is dehalogenated by the transfer of the methyl group to $\mathrm{H}_{4} \mathrm{~F}$ (catalyzed by $\mathrm{CmuA}$ and $\mathrm{CmuB}$ in the strain CM4) (Studer et al. 2001), which is then further oxidized via the $\mathrm{H}_{4} \mathrm{~F}$-dependent pathway using specific enzymes (Studer et al. 2002). Dichloromethane is converted to $S$-chloromethyl glutathione and inorganic chloride by dichloromethane dehydrogenase (DcmA in the strain DM4) (Leisinger et al. 1994). The instable $S$-chloromethyl glutathione decomposes spontaneously to formaldehyde, inorganic chloride, and glutathione (Muller et al. 2011).

\section{Facultative methylotrophy and co-consumption of substrates}

As mentioned above, $M$. extorquens is a facultative methylotroph. The alternative non-C1 growth substrates, which have been investigated in detail, are succinate (C4), acetate (C2), and oxalate (C2). Succinate and acetate enter the metabolism on the level of the TCA, and in both cases gluconeogenesis is employed to produce sugars. In the case of growth on acetate, glyoxylate needs to be regenerated via the EMCP (Schneider et al. 2012a). Oxalate is converted to oxalyl-CoA, which is decarboxylated to formyl-CoA and further metabolized via a variant of the serine cycle where glyoxylate is provided by the reduction of oxalyl-CoA (Schneider et al. 2012b). A recent study investigated the activities of all enzymes involved in methanol assimilation under C1, C2, and C4 substrate conditions (Smejkalova et al. 2010).

It can be expected that $M$. extorquens needs to switch carbon sources regularly in its natural environment depending on carbon availability. The adaptation involved in such a switch from multi-carbon (succinate) to single carbon (methanol) was investigated using a systems-level approach (Skovran et al. 2010). This study revealed that immediately after the substrate switch a significant amount of methanol is oxidized to formate and further to $\mathrm{CO}_{2}$. It was proposed that $M$. extorquens uses a downstream priming approach; i.e. the assimilation cycles (serine cycle and EMCP) are induced before the pathways delivering the corresponding precursors $\left(\mathrm{H}_{4} \mathrm{~F}\right.$-dependent pathway). The study also identified potential control points including the conversion of methenylto methylene- $\mathrm{H}_{4} \mathrm{~F}$ (catalyzed by MtdA) and the conversion of mesaconyl-CoA to $\beta$-methylmalyl-CoA (catalyzed by Mcd). The expression of the latter is initially decreased but later increased again, suggesting that in this way the buildup of the toxic intermediate glyoxylate, which is produced in the subsequent step, is blocked. Interestingly, the expression of genes common for both growth substrates is changed greatly 
during the switch, but the metabolite pools are relatively constant, suggesting the presence of metabolic set points (Skovran et al. 2010).

In addition to alternative carbon utilization and substrate switches, mixed substrate availability has also been examined. Interestingly, succinate and methanol are co-consumed (Peyraud et al. 2012) if fed simultaneously to a batch culture. This is achieved by partitioning of methanol and succinate to specific metabolic pathways. Methanol is primarily used for energy generation via linear oxidation and dedicated biosynthetic reactions involving $\mathrm{C} 1$ precursors such as purine biosynthesis (Peyraud et al. 2012). Succinate is mainly used to provide precursors for biomass production with the concomitant production of reducing equivalents that can be used for ATP generation. The repression of methanol assimilation occurred at the level of the serine cycle, and no operation of the EMCP was observed. It was suggested that co-consumption is a strategy to optimize substrate utilization under environmental conditions (Peyraud et al. 2012).

Taken together, these findings suggest that the metabolism of the facultative methylotroph is optimized to exploit the availability of methanol at any time. This is additionally supported by the fact that $\mathrm{MxaF}$ is the most abundant protein not only on $\mathrm{C} 1$ but also on multi-carbon substrates (Bosch et al. 2008).

\section{Regulation of methylotrophic pathways}

Several transcriptional regulators for methylotrophy have been identified thus far. Each of the gene clusters involved in methanol oxidation ( $m x a, m x b, m x c)$ are transcribed in one unit, and the promoter regions for the $m x a$ and $m x b$ cluster have been identified (showing similarity to the Escherichia coli $\mathrm{o}^{70}$ promoter consensus) (Zhang and Lidstrom 2003). In addition, a multiple A-tract regulatory sequence was identified upstream of the promoter regions of five methanol oxidation genes and is essential for normal expression of these genes (Zhang et al. 2005). Five essential genes encoded together with methanol oxidation genes are involved in the regulation of gene expression. The $m x b D M$ genes are involved in transcriptional regulation ( $m x b M$ encodes for a response regulator, $m x b D$ for a sensor kinase) of different methanol oxidation genes including $m x a F, p q q E$, and mxaW (Springer et al. 1997). Another regulator-sensor pair involved in $m x a F$ transcription is encoded by mxcQE (Springer et al. 1995). One of these couples $(m x c Q E)$ positively regulates the expression of the other $(m x b D M)$ (Springer et al. 1997). The knockout mutants of $m x c Q E$ and especially $m x b D M$ do not express cytochrome $c_{\mathrm{L}}$ but an alternative cytochrome termed $c_{553}$ (Springer et al. 1995), suggesting that $c_{553}$ is negatively regulated by $m x b D M$. Another gene, $m x a B$, shows homology to response regulators (Springer et al. 1998) and is required for the expression of mxaF (Morris and Lidstrom 1992). Two additional genes involved in the regulation of methanol oxidation are the $m x a F$-homologs $x o x F 1$ and $x o x F 2$, which appear to fulfill a dual role: a catalytic role (see methanol oxidation chapter) and a regulatory role (Skovran et al. 2011). The double mutant of $x o x F 12$ is not able to grow on methanol and shows decreased expression of $m x b D M$ and $m x c Q E$, suggesting that it functions via these regulators (Skovran et al. 2011).

A LysR-type transcriptional regulator, QscR, positively controls the expression of the two serine cycle operons: qsc1 (sga, hpr, mtdA, fch) and qsc2 ( $m t k A B, p p c, m c l A)$ and the separate gene gly $A$. The expression of genes that are also involved in central metabolism ( $m d h$ and eno) was not regulated by QscR (Kalyuzhnaya and Lidstrom 2003, 2005). The expression of $q s c R$ is independent of the growth substrate, but the DNA-binding activity of QscR is increased by formyl- $\mathrm{H}_{4} \mathrm{~F}$ and decreased by NADP ${ }^{+}$and acetyl-CoA (Kalyuzhnaya and Lidstrom 2005). Surprisingly, a recent proteomics study revealed that QscR is strongly down-regulated on methanol (Bosch et al. 2008). Further investigation will be required to understand this finding.

Unlike other methylotrophy genes, the genes of the EMCP are not transcribed in operons (Hu and Lidstrom 2012) and are expressed in multiple patterns during a substrate switch from succinate to methanol and not as a unit (Skovran et al. 2010). Very little is known about their regulation. Recently, a TetR family regulator for the expression of $c c r$, encoding for a key enzyme of the EMCP, was discovered and termed CcrR. Interestingly, this regulator did not affect other genes of the EMCP (Hu and Lidstrom 2012).

\section{M. extorquens in biotechnology}

The profound knowledge of the metabolism, proteome, genome, and transcriptome of $M$. extorquens, in addition to the availability of genetic tools and well-established bioprocess regimes, makes this bacterium an attractive candidate for the bioproduction of chemicals from non-sugar substrates (see Fig. 2). Such value-added products might be general substances from precursors common to all organisms such as amino acids, or products based on specific intermediates of the metabolism of $M$. extorquens, including PHB or EMCP intermediates, for the biosynthesis of novel dicarboxylic acids, polyketides, or butanol.

A further benefit of $M$. extorquens as production host is the standard use of minimal media, which significantly facilitates product recovery during downstream processing compared to conventional bioprocesses, where complex carbon sources, such as molasses or corn steep liquor, are often employed. The toxicity of methanol is another advantage, as most microbes are not able to grow and therefore to contaminate 


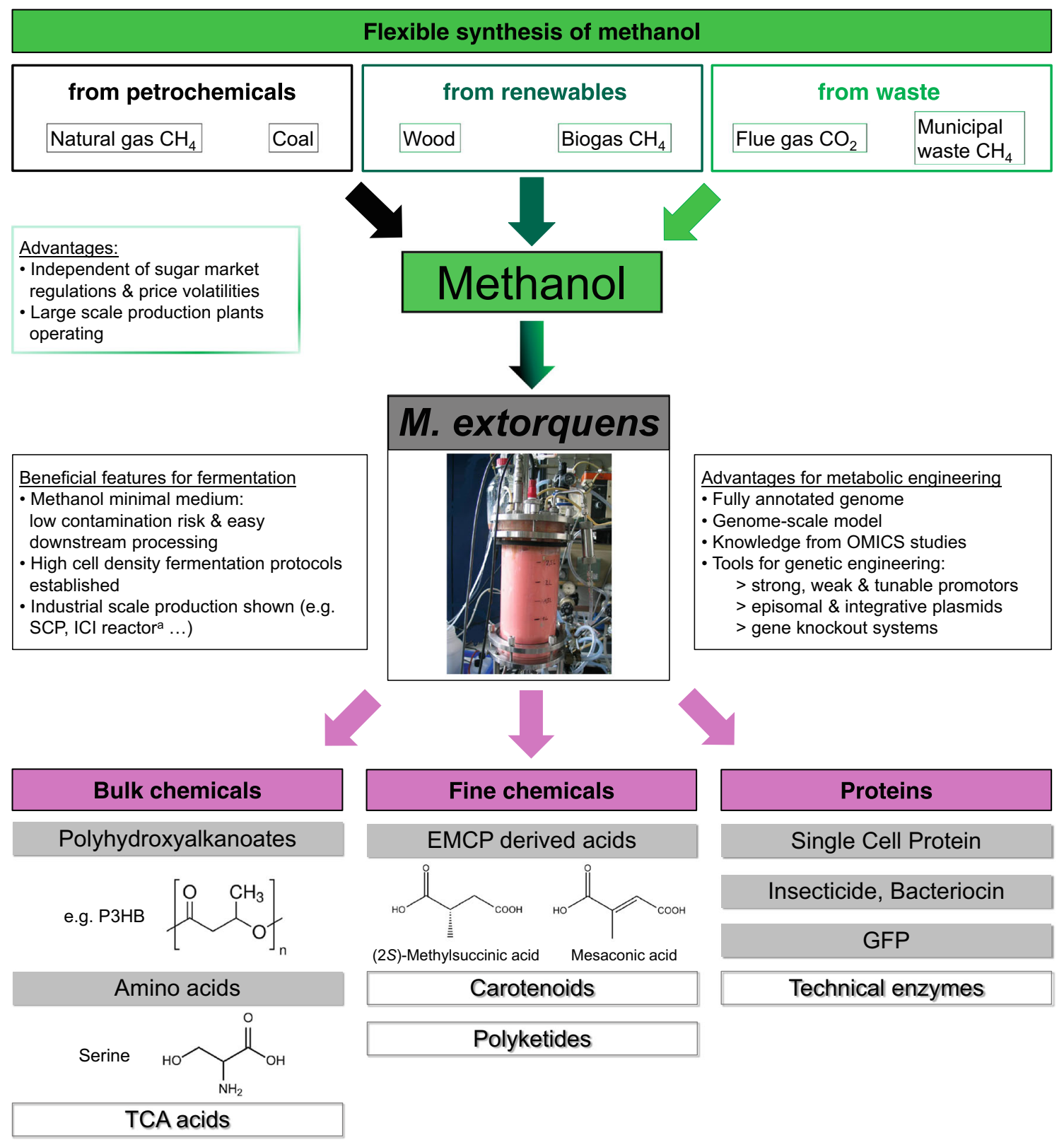

Fig. 2 Use of $M$. extorquens as microbial host for methanol-based product syntheses. Established products are shaded in gray, potential products in white. Please refer to Table 4 for references of the distinct

methanol minimal media-based fermentation processes. Although $M$. extorquens is able to utilize a wide range of different carbon sources consisting of one-, two-, three-, four-, or five-carbon atoms including alcohols, amines, mono-, and dicarboxylic acids (see Table S1), all the reported biotechnological processes established with $M$. extorquens thus far are based on the substrate methanol. A recent exception is the synthesis of 1-butanol using ethylamine (see Table 4). In addition to methanol, (bio-)ethanol might also become an attractive alternative as a non-sugar-based (and renewable) substrate for the biotechnological production of chemicals by M. extorquens. However, no ethanol-based process has been reported to date. processes. ${ }^{\text {a }}$ single cell protein production by Imperial Chemical Industries in 1,500 $\mathrm{m}^{3}$ air-lift reactor performed in the $1970 \mathrm{~s}$ and $1980 \mathrm{~s}$ (Senior and Windass 1980)

In this respect, it should be noted that the maximum growth rates on methanol, which varied from 0.169 to $0.19 \mathrm{~h}^{-1}$ (Bélanger et al. 2004; Peyraud et al. 2011), are considerably higher than the $0.069 \mathrm{~h}^{-1}$ reported for growth on ethanol (Dunstan et al. 1972). The slow growth of M. extorquens AM1 on ethanol is a drawback for competitive industrial applications. In this respect, strain PA1 might represent an attractive alternative candidate with higher growth rates on methanol, ethanol, and multi-carbon substrates (Nayak and Marx 2014a).

Until now, $M$. extorquens has been used for the biotechnological production of various chemicals from methanol, such as polyhydroxyalkanoates (precisely polyhydroxybutyrates), 


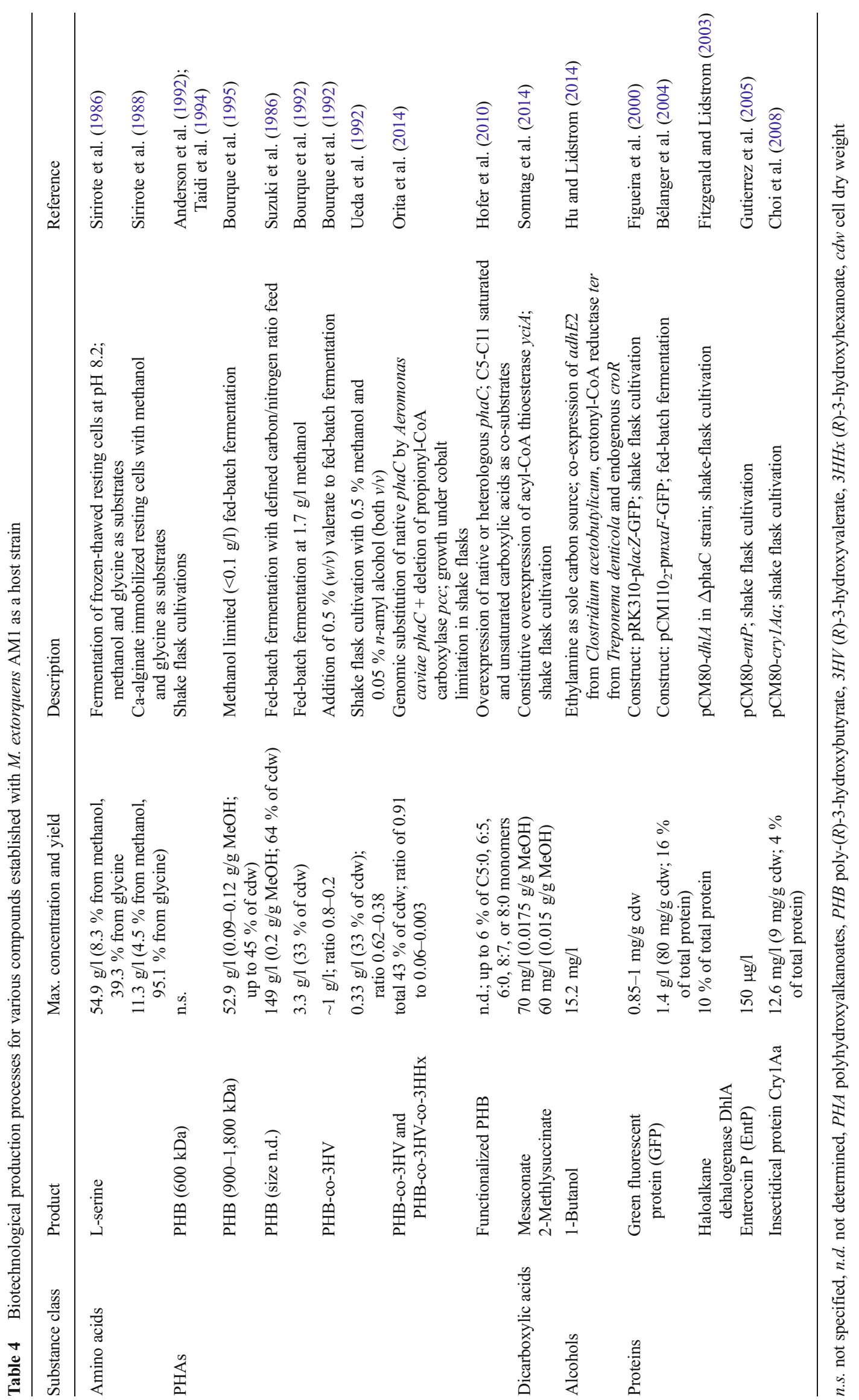


amino acids, dicarboxylic acids, as well as proteins and alcohols from ethylamine (see Table 4). Here, we provide an overview regarding all the reported bioprocesses using M. extorquens followed by a short assessment of the future potential of $M$. extorquens as a microbial production host.

One group of bulk chemicals are polymers, such as polyhydroxyalkanoates (PHAs), which have a wide range of applications in packaging, medicine, or as textile and household materials (Keshavarz and Roy 2010). M. extorquens is a natural producer of poly-3-hydroxybutyrate (P3HB), whose production from methanol has been investigated for more than 25 years. Suzuki and colleagues reached a remarkable concentration of $149 \mathrm{~g} / 1 \mathrm{P} 3 \mathrm{HB}(64 \%$ of cell dry weight (cdw)) at a yield of $0.2 \mathrm{~g} / \mathrm{g}$ methanol in 1986. Similar yields and total amounts were later achieved by Mokhtari-Hosseini et al. (2009). Both groups used accurately adjusted methanol and nitrogen-limited fed-batch fermentations of $M$. extorquens. The total amounts, yield per hour or yield per cdw of produced PHB by M. extorquens, are the highest reported compared to other one-carbon- (carbon dioxide, methane, or methanol) based production processes (Khosravi-Darani et al. 2013). Even in comparison to classic production hosts, such as Cupriavidis necator (former Ralstonia eutropha) or recombinant $E$. coli converting non C1-carbon sources up to $180 \mathrm{~g} / 1$ $\mathrm{PHB}$, the production outcomes described for $M$. extorquens were in the same range, although space time yields were lower (Chen 2009). Pure P3HB has, however, only limited fields of application due to its stiffness and brittleness caused by its high crystallinity (Verlinden et al. 2007). Investigations of copolymerization with other hydroxyalkanoate co-monomer(s), which overcome the poor mechanical properties of pure $\mathrm{P} 3 \mathrm{HB}$, were therefore carried out and successfully established by the addition of valerate or n-amyl alcohols to the medium (Bourque et al. 1992; Ueda et al. 1992). The production of an even wider range of functionalized PHBs was established using a combination of different native or heterologously expressed PHB synthases and saturated or unsaturated carboxylic acids as co-substrates (Hofer et al. 2010). However, one must be aware that the addition of precursors increases the production costs, which is especially unfavorable for bulk chemicals such as PHBs. A recent study described the de novo production of the copolymer poly[(3hydroxybutyrate-co-3-hydroxyvalerate] and the terpolymer poly [(3-hydroxybutyrate-co-3-hydroxyvalerate-co-3hydroxyhexanoate)] by a metabolically engineered M. extorquens strain growing under cobalt-limited conditions (Orita et al. 2014). Cobalt limitation provides limited flux through the EMCP (Chou et al. 2009; Kiefer et al. 2009), resulting in higher pools of propionyl- and butyryl-CoA, which act as precursors for PHB functionalization. Although the PHA content of the cells is still lower than shown for pure $\mathrm{P} 3 \mathrm{HB}$ (see Table 4) production processes, newly available tools, e.g., plasmids harboring inducible promoters, (see Table 2) for metabolic engineering might enable higher yields for the production of functionalized PHAs from methanol in the future.

Amino acids are also considered as chemical bulk products with an overall worldwide market volume of more than 3 million tons per year (Sanchez and Demain 2008). Most of the commercially available amino acids are produced by microbial fermentations, such as serine, which is mainly used in pharmaceutical and cosmetic industry and as a building block for the chemical industry (Ikeda 2003). In contrast to other amino acids such as lysine or glutamate, serine is a central metabolic intermediate and precursor for many other metabolites in the classical amino acid producer Corynebacterium glutamicum. This has been a drawback for large-scale and high-yield de novo production of serine; thus, despite intense metabolic engineering efforts, the produced serine concentrations of $36.5 \mathrm{~g} / \mathrm{l}$ (Stolz et al. 2007) are still comparatively low. Methylotrophs harboring the serine cycle, such as $M$. extorquens, offer the possibility to produce serine directly out of cheap methanol and glycine because glycine serves as acceptor molecule for methylene $\mathrm{H}_{4} \mathrm{~F}$ leading to serine (see above). Sirriote and coworkers used immobilized freeze-thawed resting cells of $M$. extorquens in a controlled fermentation process to produce serine (Sirirote et al. 1988; Sirirote et al. 1986). Freeze-thawing causes porous cell membranes and enables serine export over the cellular membrane. The fermentation of freeze-thawed cells was carried out at methanol concentrations high enough to inhibit growth of M. extorquens but below the lethal dose. Thus, biomass formation was prevented and remarkable serine product concentrations of $54.9 \mathrm{~g} / \mathrm{l}$ were achieved. Today's processes are based on Methylobacterium sp. MN43 (Hagishita et al. 1996), which has been reported to produce up to $65 \mathrm{~g} / 1$ serine. Further increases might be possible by the application of presently available genetic tools, although the challenges of registering food additives produced by genetically modified organisms must be considered.

The heterologous production of (recombinant) proteins is a multi-billion dollar market ranging from pharmaceutical proteins to industrial enzymes (Goodman 2009; Group F 2009). Only approximately $50 \%$ of biopharmaceutical proteins are produced in bacteria (mostly E. coli) or yeast (mostly Saccharomyces cerevisiae) (Ferrer-Miralles et al. 2009), whereas industrial enzymes are produced by fungi (e.g., Aspergillus spp.), yeast (e.g., S. cerevisiae, Pichia pastoris), or bacteria (e.g., Bacillus spp., E. coli) (Adrio and Demain 2010). Using M. extorquens for the production of enzymes or recombinant proteins from the carbon source methanol would be an interesting alternative to conventional sugar-based production processes as the use of substrates competing with food production could be avoided and product recovery facilitated by the use of minimal medium and the relatively "clean" supernatant of M. extorquens cultures. 
To date, the heterologous production of four different proteins by $M$. extorquens (GFP, insecticidal protein Cry1Aa, a haloalkane dehalogenase, and Enterocin P) has been reported (see Table 4). These studies provide a proof-of-concept for the applicability of $M$. extorquens as a production host for different heterologous proteins. However, protein yields and final concentrations vary highly from microgram per liter scale for Enterocin P to $1.4 \mathrm{~g} / 1$ (16\% of total protein) reported for GFP by Bélanger et al. (2004). Commercial production processes would require considerably higher yields because yields up to $50 \%$ of cdw and product concentrations of more than $5 \mathrm{~g} / 1$ protein were achieved for E. coli (Panda 2003) and methylotrophic yeast $P$. pastoris (Macauley-Patrick et al. 2005), respectively. It must also be considered that the use of M. extorquens as a bacterial host has several disadvantages compared to already established methylotrophic yeast $P$. pastoris, such as a lacking posttranscriptional modification machinery. In particular, more research concerning the protein secretion machinery of $M$. extorquens would be needed to adjust its capabilities to the purpose of high-efficiency protein production. Nevertheless, $M$. extorquens might be very suitable for the production of industrial enzymes due to its relatively "clean" supernatant.

In addition to the possibility of producing long-known bulk chemicals from the alternative carbon source methanol, the $\mathrm{C} 1$ metabolism of M. extorquens itself provides potential precursors for the production of special chemical compounds. One rather unusual pathway is the EMCP (see above), which comprises of several branched, saturated or unsaturated, and in some cases, chiral C4- and C5-acyl-CoA esters (Erb et al. 2007; Peyraud et al. 2009). Their corresponding dicarboxylic acids, e.g., ethylmalonic acid, $(2 S)$ methylsuccinic acid, mesaconic acid, or $(2 R / 3 S)$ methylmalic acid, represent new and interesting building blocks for the chemical industry (Alber 2011). Recently, a bacterial thioesterase YciA was identified that is capable of cleaving CoA from mesaconyl- and (2S)methylsuccinyl-CoA, resulting in de novo production of mesaconic and 2-methylsuccinic acid from methanol (Sonntag et al. 2014). Although still in the milligram per liter range, EMCP-derived dicarboxylic acid production offers the possibility of the sustainable production of novel monomers. The research to increase process efficiency is currently ongoing in our laboratories.

Beside the dicarboxylic acid derivatives, the EMCP intermediates can also be used as precursors for the biosynthesis of next generation fuels. $\mathrm{Hu}$ and Lidstrom (2014) used a combined overexpression of a crotonoyl-CoA reductase and alcohol dehydrogenase for the production of 1-butanol out of crotonyl-CoA. Interestingly, these approach required ethylamine as carbon source instead of methanol to synthesize detectable butanol concentrations. Further optimization might not only increase the product concentrations which are in low miligram per liter range but also enable the use of methanol as carbon source.

Taken together, M. extorquens is an efficient bacterial host for the production of various chemical compounds starting from methanol as shown by the synthesis of (functionalized) PHB, amino acid serine, proteins, and uncommon dicarboxylic acids. Final product concentrations and yields are often already competitive, and the increasing interest in the use of alternative carbon sources will most likely focus efforts on establishing application processes with the methylotroph M. extorquens.

\section{Future potential of $M$. extorquens as production host}

Proof of concepts for the production of PHAs, amino acids, proteins, and dicarboxylic acids from methanol by M. extorquens have been delivered to date. In these laboratory processes, product concentrations and yields for PHB and serine synthesis have already reached high values. Nevertheless, new available genetic tools and metabolic insights might provide possibilities to maximize the efficiency of these processes.

The natural PHB synthesis pathway in M. extorquens will likely play a key role for the further optimization of de novo production processes, as PHB is in most cases an unwanted by-product. This is particularly true for the production of EMCP-derived dicarboxylic acids due to an overlap of the PHB cycle and EMCP (see Fig. 1). Knockout of the PHB synthase gene $p h a C$ was already described by Korotkova and Lidstrom (2001), but this mutant suffered from a strong growth defect and was highly instable because it produced second-site suppressor mutants at a high frequency. A deeper insight into PHB synthesis regulation showed that regulator protein $\mathrm{PhaR}$ might act as a central flux regulator for acetyl-CoA adjusting its distribution either to the EMCP and therefore also to PHB or to the TCA cycle (Korotkova et al. 2002b). The knockout strain $\triangle p h a R$ is as a stable mutant unable to produce PHB, but metabolomics revealed increased flux through the TCA (Van Dien et al. 2003), which is likely disadvantageous for increasing EMCP-related product formation. A deeper understanding of the mechanism of PhaR may not only provide a way to establish a stable PHB-synthase knockout strain without drastic growth defect, but may also be useful for the controlled increase of TCA fluxes. The latter may open opportunities for TCA cycle-derived dicarboxylic acid or amino acid production from methanol by $M$. extorquens.

In addition to mesaconic acid and (2S)-methylsuccinic acid, other EMCP-derived dicarboxylic acids, such as ethylmalonic acid, methylmalonic acid, or the chiral $(2 R /$ 3S)-methylmalic acid (Alber 2011), are interesting chemical building blocks unavailable in bulk quantities to date. Their production would require another thioesterase that ideally has 
specific activity with one of the related CoA-esters. As in vitro screens are hindered by the fact that many (EMCP) CoAesters are expensive or commercially unavailable, in vivo screening of potential thioesterases might be an option. McMahon and Prather (2014) recently published a screen for thioesterases showing increased activity in comparison to broad-range thioesterase TesB. They expressed different thioesterases in an engineered $E$. coli strain harboring a heterologous pathway with several short-chain acyl-CoA intermediates followed by supernatant analysis for an altered spectrum of released acids or alcohols as the cleave-off products of the acyl-CoAs. This method is most likely also applicable for screening thioesterases active on CoA-ester intermediates of the EMCP in M. extorquens. However, lethal effects resulting from unspecific cleavage of essential CoA-esters and insufficient CoA-ester pools for measurable acid concentrations must be taken into consideration when applying this approach.

Along with the function as precursors for the production of novel dicarboxylic acids, CoA-esters of the EMCP, especially ethyl- and methylmalonyl-CoA, could act as monomers for heterologous polyketide synthesis, as they are the most important building blocks for polyketide synthases (Wilson and Moore 2012). Sufficient supply of heterologous polyketide synthesis in E. coli or other hosts often suffers from the low amount of available precursors (e.g., methylmalonyl-CoA) or their complete inexistence (e.g., ethylmalonyl-CoA in E. coli). Therefore, the expensive addition of necessary substrates or the high effort of establishing additional pathways for polyketide precursor synthesis is required (Gao et al. 2010; Pfeifer and Khosla 2001). This could be avoided by using M. extorquens as a host for polyketide biosynthesis, as most of the known precursors such as acetyl-, methylmalonyl-, ethylmalonyl-, malonyl-, and propionyl- are part of the primary metabolism with high metabolic fluxes and likely comparatively high pool sizes. However, the functional expression of a heterologous polyketide synthases in M. extorquens has not been proven to date.

M. extorquens is a pink-pigmented methylotroph (Peel and Quayle 1961), and the color is a result of natural carotenoid production, which are likely C30 carotenoids instead of common C40 carotenoids (Sandmann, unpublished). As a native carotenoid producer, $M$. extorquens might be suitable for the production of other commercially interesting carotenoids such as $\beta$-carotene. However, exact information on the natural carotenoid biosynthesis, which most likely overlaps with hopane biosynthesis (Bradley et al. 2010), would be necessary for efficient pathway manipulation.

In summary, there is tremendous potential for $M$. extorquens to be applied as a microbial cell factory for the synthesis of various compounds from methanol, in addition to the already established processes (see above). In addition to other bulk chemicals such as TCA- or EMCP-derived dicarboxylic acid,
M. extorquens metabolism also offers an opportunity for the production of fine chemicals such as polyketides, carotenoids, or terpenoids.

Acknowledgments Work related to methylotrophy in the authors' laboratories is supported by a grant from FP7 project "Promyse" and a grant from the Swiss SystemsX.ch initiative within the framework of the ERANet ERASysAPP, MetApp.

\section{References}

Abanda-Nkpwatt D, Musch M, Tschiersch J, Boettner M, Schwab W (2006) Molecular interaction between Methylobacterium extorquens and seedlings: growth promotion, methanol consumption, and localization of the methanol emission site. J Exp Bot 57:4025-4032

Acharya P, Goenrich M, Hagemeier CH, Demmer U, Vorholt JA, Thauer RK, Ermler U (2005) How an enzyme binds the $\mathrm{C}_{1}$ carrier tetrahydromethanopterin. Structure of the tetrahydromethanopterin-dependent formaldehyde-activating enzyme (Fae) from Methylobacterium extorquens AM1. J Biol Chem 280:13712-13719

Adrio JL, Demain AL (2010) Recombinant organisms for production of industrial products. Bioeng Bugs 1:116-131

Alber BE (2011) Biotechnological potential of the ethylmalonyl-CoA pathway. Appl Microbiol Biotechnol 89:17-25

Alber BE, Spanheimer R, Ebenau-Jehle C, Fuchs G (2006) Study of an alternate glyoxylate cycle for acetate assimilation by Rhodobacter sphaeroides. Mol Microbiol 61:297-309

Anderson AJ, Williams DR, Taidi B, Dawes EA, Ewing DF (1992) Studies on copolyester synthesis by Rhodococcus ruber and factors influencing the molecular mass of polyhydroxybutyrate accumulated by Methylobacterium extorquens and Alcaligenes eutrophus. FEMS Microbiol Lett 103:93-101

Anthony C (1982) The biochemistry of methylotrophs. Academic, London

Anthony C (1986) Bacterial oxidation of methane and methanol. Adv Microb Physiol 27:113-210

Anthony C (1992) The $c$-type cytochromes of methylotrophic bacteria. Biochim Biophys Acta 1099:1-15

Anthony C (2011) How half a century of research was required to understand bacterial growth on $\mathrm{C}_{1}$ and $\mathrm{C}_{2}$ compounds; the story of the serine cycle and the ethylmalonyl-CoA pathway. Sci Prog 94: 109-137

Anthony C, Williams P (2003) The structure and mechanism of methanol dehydrogenase. Biochim Biophys Acta 1647:18-23

Bélanger L, Figueira MM, Bourque D, Morel L, Béland M, Laramée L, Groleau D, Miguez CB (2004) Production of heterologous protein by Methylobacterium extorquens in high cell density fermentation. FEMS Microbiol Lett 231:197-204

Bertau M, Offermanns H, Plass L, Schmidt F, Wernicke H-J (2014) Methanol: the basic chemical and energy feedstock of the future, vol 1. Springer, Heidelberg

Bosch G, Skovran E, Xia Q, Wang T, Taub F, Miller JA, Lidstrom ME, Hackett M (2008) Comprehensive proteomics of Methylobacterium extorquens AM1 metabolism under single carbon and nonmethylotrophic conditions. Proteomics 8:3494-3505

Bourque D, Ouellette B, André G, Groleau D (1992) Production of poly$\beta$-hydroxybutyrate from methanol: characterization of a new isolate of Methylobacterium extorquens. Appl Microbiol Biotechnol 37:712

Bourque D, Pomerleau Y, Groleau D (1995) High-cell density production of poly-b-hydroxybutyrate (PHB) from methanol by 
methylobacterium extorquens: production of high-molecular-mass PHB. Appl Microbiol Biotechnol 44:197-204

Bradley AS, Pearson A, Sáenz JP, Marx CJ (2010) Adenosylhopane: the first intermediate in hopanoid side chain biosynthesis. Org Geochem 41:1075-1081

Caccamo MA, Malone CS, Rasche ME (2004) Biochemical characterization of a dihydromethanopterin reductase involved in tetrahydromethanopterin biosynthesis in Methylobacterium extorquens AM1. J Bacteriol 186:2068-2073

Carroll SM, Xue KS, Marx CJ (2014) Laboratory divergence of Methylobacterium extorquens AM1 through unintended domestication and past selection for antibiotic resistance. BMC Microbiol 14:2

Chen G-Q (2009) A microbial polyhydroxyalkanoates (PHA) based bioand materials industry. Chem Soc Rev 38:2434-2446

Chistoserdov AY, Chistoserdova LV, McIntire WS, Lidstrom ME (1994) Genetic organization of the mau gene cluster in Methylobacterium extorquens AM1: complete nucleotide sequence and generation and characteristics of mau mutants. J Bacteriol 176:4052-4065

Chistoserdova L (2011) Modularity of methylotrophy, revisited. Environ Microbiol 13:2603-2622

Chistoserdova LV, Lidstrom ME (1992) Cloning, mutagenesis, and physiological effect of a hydroxypyruvate reductase gene from Methylobacterium extorquens AM1. J Bacteriol 174:71-77

Chistoserdova L, Lidstrom ME (1997) Molecular and mutational analysis of a DNA region separating two methylotrophy gene clusters in Methylobacterium extorquens AM1. Microbiology 143(Pt 5):1729 1736

Chistoserdova L, Lidstrom M (2013) Aerobic methylotrophic prokaryotes. In: Rosenberg E, DeLong EF, Thompson F, Lory S, Stackebrandt E (eds) The prokaryotes, 4th edn. Springer, New York, pp 267-285

Chistoserdova L, Vorholt JA, Thauer RK, Lidstrom ME (1998) $C_{1}$ transfer enzymes and coenzymes linking methylotrophic bacteria and methanogenic Archaea. Science 281:99-102

Chistoserdova L, Chen SW, Lapidus A, Lidstrom ME (2003) Methylotrophy in Methylobacterium extorquens AM1 from a genomic point of view. J Bacteriol 185:2980-2987

Chistoserdova L, Laukel M, Portais JC, Vorholt JA, Lidstrom ME (2004) Multiple formate dehydrogenase enzymes in the facultative methylotroph Methylobacterium extorquens AM1 are dispensable for growth on methanol. J Bacteriol 186:2228

Chistoserdova L, Rasche ME, Lidstrom ME (2005a) Novel dephosphotetrahydromethanopterin biosynthesis genes discovered via mutagenesis in Methylobacterium extorquens AM1. J Bacteriol 187:2508-2512

Chistoserdova L, Vorholt JA, Lidstrom ME (2005b) A genomic view of methane oxidation by aerobic bacteria and anaerobic archaea. Genome Biol 6:208

Chistoserdova L, Crowther GJ, Vorholt JA, Skovran E, Portais JC, Lidstrom ME (2007) Identification of a fourth formate dehydrogenase in Methylobacterium extorquens AM1 and confirmation of the essential role of formate oxidation in methylotrophy. J Bacteriol 189:9076-9081

Choi YJ, Morel L, Bourque D, Mullick A, Massie B, Miguez CB (2006) Bestowing inducibility on the cloned methanol dehydrogenase promoter $\left(\mathrm{P}_{\mathrm{mxaF}}\right)$ of Methylobacterium extorquens by applying regulatory elements of Pseudomonas putida F1. Appl Environ Microbiol 72:7723-7729

Choi YJ, Gringorten JL, Belanger L, Morel L, Bourque D, Masson L, Groleau D, Miguez CB (2008) Production of an insecticidal crystal protein from Bacillus thuringiensis by the methylotroph Methylobacterium extorquens. Appl Environ Microbiol 74:51785182

Chou HH, Marx CJ (2012) Optimization of gene expression through divergent mutational paths. Cel Rep 1:133-140
Chou H-H, Berthet J, Marx CJ (2009) Fast growth increases the selective advantage of a mutation arising recurrently during evolution under metal limitation. PLoS Genet 5:e1000652

Chubiz LM, Purswani J, Carroll SM, Marx CJ (2013) A novel pair of inducible expression vectors for use in Methylobacterium extorquens. BMC Res Notes 6:183

Crowther GJ, Kosaly G, Lidstrom ME (2008) Formate as the main branch point for methylotrophic metabolism in Methylobacterium extorquens AM1. J Bacteriol 190:5057-5062

Dedysh SN, Dunfield PF, Trotsenko YA (2004) Methane utilization by Methylobacterium species: new evidence but still no proof for an old controversy. Int J Syst Evol Microbiol 54:1919-1920

Delaney NF, Kaczmarek ME, Ward LM, Swanson PK, Lee MC, Marx CJ (2013) Development of an optimized medium, strain and highthroughput culturing methods for Methylobacterium extorquens. PLoS One 8:e62957

Delmotte N, Knief C, Chaffron S, Innerebner G, Roschitzki B, Schlapbach R, von Mering C, Vorholt JA (2009) Community proteogenomics reveals insights into the physiology of phyllosphere bacteria. Proc Natl Acad Sci U S A 106:16428-16433

Doronina NVSA, Trotsenko YA (1996) Isolation and initial characterization of aerobic chloromethane-utilizing bacteria. FEMS Microbiol Lett 179-183

Dunstan PM, Anthony C (1973) Microbial metabolism of $\mathrm{C}_{1}$ and $\mathrm{C}_{2}$ compounds. The role of acetate during growth of Pseudomonas AM1 on $\mathrm{C}_{1}$ compounds, ethanol and $\beta$-hydroxybutyrate. Biochem J 132:797-801

Dunstan PM, Anthony C, Drabble WT (1972) Microbial metabolism of $\mathrm{C}_{1}$ and $\mathrm{C}_{2}$ compounds. The role of glyoxylate, glycollate and acetate in the growth of Pseudomonas AM1 on ethanol and on $\mathrm{C}_{1}$ compounds. Biochem J 128:107-115

Erb TJ, Berg IA, Brecht V, Muller M, Fuchs G, Alber BE (2007) Synthesis of $\mathrm{C}_{5}$-dicarboxylic acids from $\mathrm{C}_{2}$-units involving crotonyl-CoA carboxylase/reductase: the ethylmalonyl-CoA pathway. Proc Natl Acad Sci U S A 104:10631-10636

Erb TJ, Retey J, Fuchs G, Alber BE (2008) Ethylmalonyl-CoA mutase from Rhodobacter sphaeroides defines a new subclade of coenzyme $B_{12}$-dependent acyl-CoA mutases. J Biol Chem 283:32283-32293

Ermler U, Hagemeier CH, Roth A, Demmer U, Grabarse W, Warkentin E, Vorholt JA (2002) Structure of methylene-tetrahydromethanopterin dehydrogenase from Methylobacterium extorquens AM1. Structure 10:1127-1137

Escalante-Semerena JC, Rinehart KL Jr, Wolfe RS (1984) Tetrahydromethanopterin, a carbon carrier in methanogenesis. J Biol Chem 259:9447-9455

Ettwig KF, Butler MK, Le Paslier D, Pelletier E, Mangenot S, Kuypers MM, Schreiber F, Dutilh BE, Zedelius J, de Beer D, Gloerich J, Wessels HJ, van Alen T, Luesken F, Wu ML, van de Pas-Schoonen KT, Op den Camp HJ, Janssen-Megens EM, Francoijs KJ, Stunnenberg H, Weissenbach J, Jetten MS, Strous M (2010) Nitrite-driven anaerobic methane oxidation by oxygenic bacteria. Nature 464:543-548

Fall R, Benson AA (1996) Leaf methanol - the simplest natural product from plants. Trends Plant Sci 1:296-301

Fedorov DN, Doronina NV, Trotsenko Iu A (2011) Phytosymbiosis of aerobic methylobacteria: new facts and views. Mikrobiologiia 80: 435-446

Ferrer-Miralles N, Domingo-Espin J, Corchero J, Vazquez E, Villaverde A (2009) Microbial factories for recombinant pharmaceuticals. Microb Cell Fact 8:17

Figueira MM, Laramee L, Murrell JC, Groleau D, Miguez CB (2000) Production of green fluorescent protein by the methylotrophic bacterium Methylobacterium extorquens. FEMS Microbiol Lett 193: 195-200

Fitzgerald KA, Lidstrom ME (2003) Overexpression of a heterologous protein, haloalkane dehalogenase, in a poly- $\beta$-hydroxybutyrate- 
deficient strain of the facultative methylotroph Methylobacterium extorquens AM1. Biotechnol Bioeng 81:263-268

Gao X, Wang P, Tang Y (2010) Engineered polyketide biosynthesis and biocatalysis in Escherichia coli. Appl Microbiol Biotechnol 88: $1233-1242$

Goodman M (2009) Market watch: sales of biologics to show robust growth through to 2013. Nat Rev Drug Discov 8:837

Group F (2009) World enzymes to 2013. The Freedonia Group, Inc, Cleveland

Gruffaz C, Muller EE, Louhichi-Jelail Y, Nelli YR, Guichard G, Bringel F (2014) Genes of the $N$-methylglutamate pathway are essential for growth of Methylobacterium extorquens DM4 with monomethylamine. Appl Environ Microbiol 80:3541-3550

Guo X, Lidstrom ME (2006) Physiological analysis of Methylobacterium extorquens AM1 grown in continuous and batch cultures. Arch Microbiol 186:139-149

Guo X, Lidstrom ME (2008) Metabolite profiling analysis of Methylobacterium extorquens AM1 by comprehensive twodimensional gas chromatography coupled with time-of-flight mass spectrometry. Biotechnol Bioeng 99:929-940

Gutierrez J, Bourque D, Criado R, Choi YJ, Cintas LM, Hernandez PE, Miguez CB (2005) Heterologous extracellular production of enterocin P from Enterococcus faecium P13 in the methylotrophic bacterium Methylobacterium extorquens. FEMS Microbiol Lett 248:125-131

Hagemeier CH, Chistoserdova L, Lidstrom ME, Thauer RK, Vorholt JA (2000) Characterization of a second methylene tetrahydromethanopterin dehydrogenase from Methylobacterium extorquens AM1. Eur J Biochem 267:3762-3769

Hagishita T, Yoshida T, Izumi Y, Mitsunaga T (1996) Efficient L-serine production from methanol and glycine by resting cells of Methylobacterium sp. strain MN43. Biosci Biotechnol Biochem 60:1604-1607

Heptinstall J, Quayle JR (1970) Pathways leading to and from serine during growth of Pseudomonas AM1 on $\mathrm{C}_{1}$ compounds or succinate. Biochem J 117:563-572

Hofer P, Choi YJ, Osborne MJ, Miguez CB, Vermette P, Groleau D (2010) Production of functionalized polyhydroxyalkanoates by genetically modified Methylobacterium extorquens strains. Microb Cell Fact 9:70

Hu B, Lidstrom M (2012) CcrR, a TetR family transcriptional regulator, activates the transcription of a gene of the ethylmalonyl coenzyme A pathway in Methylobacterium extorquens AM1. J Bacteriol 194: 2802-2808

Hu B, Lidstrom M (2014) Metabolic engineering of Methylobacterium extorquens AM1 for 1-butanol production. Biotechnol Biofuels 7: 156

Ikeda M (2003) Amino acid production processes. Adv Biochem Eng Biotechnol 79:1-35

Joe MM, Saravanan VS, Islam MR, Sa T (2013) Development of alginate-based aggregate inoculants of Methylobacterium sp. and Azospirillum brasilense tested under in vitro conditions to promote plant growth. J Appl Microbiol. doi: 10.1111/jam.12384

Kaczmarczyk A, Vorholt JA, Francez-Charlot A (2013) Cumateinducible gene expression system for sphingomonads and other Alphaproteobacteria. Appl Environ Microbiol 79: 6795-6802

Kalyuzhnaya MG, Lidstrom ME (2003) QscR, a LysR-type transcriptional regulator and CbbR homolog, is involved in regulation of the serine cycle genes in Methylobacterium extorquens AM1. J Bacteriol 185:1229-1235

Kalyuzhnaya MG, Lidstrom ME (2005) QscR-mediated transcriptional activation of serine cycle genes in Methylobacterium extorquens AM1. J Bacteriol 187:7511-7517

Keshavarz T, Roy I (2010) Polyhydroxyalkanoates: bioplastics with a green agenda. Curr Opin Microbiol 13:321-326
Khosravi-Darani K, Mokhtari Z-B, Amai T, Tanaka K (2013) Microbial production of poly(hydroxybutyrate) from $\mathrm{C} 1$ carbon sources. Appl Microbiol Biotechnol 97:1407-1424

Kiefer P, Portais JC, Vorholt JA (2008) Quantitative metabolome analysis using liquid chromatography-high-resolution mass spectrometry. Anal Biochem 382:94-100

Kiefer P, Buchhaupt M, Christen P, Kaup B, Schrader J, Vorholt JA (2009) Metabolite profiling uncovers plasmid-induced cobalt limitation under methylotrophic growth conditions. PLoS One 4:e7831

Kiefer P, Delmotte N, Vorholt JA (2011) Nanoscale ion-pair reversedphase HPLC-MS for sensitive metabolome analysis. Anal Chem 83: $850-855$

Knief C, Frances L, Vorholt JA (2010) Competitiveness of diverse Methylobacterium strains in the phyllosphere of Arabidopsis thaliana and identification of representative models, including M. extorquens PA1. Microb Ecol 60:440-452

Kohler-Staub DH, Hartmans S, Gälli R, Suter F, Leisinger T (1986) Evidence for identical dichloromethane dehalogenases in different methylotrophic bacteria. J Gen Microbiol 28372843

Kornberg HL, Krebs HA (1957) Synthesis of cell constituents from C2units by a modified tricarboxylic acid cycle. Nature 179:988-991

Korotkova N, Lidstrom ME (2001) Connection between poly- $\beta$ hydroxybutyrate biosynthesis and growth on $\mathrm{C}_{1}$ and $\mathrm{C}_{2}$ compounds in the methylotroph Methylobacterium extorquens AM1. J Bacteriol 183:1038-1046

Korotkova N, Chistoserdova L, Kuksa V, Lidstrom ME (2002a) Glyoxylate regeneration pathway in the methylotroph Methylobacterium extorquens AM1. J Bacteriol 184:1750-1758

Korotkova N, Chistoserdova L, Lidstrom ME (2002b) Poly- $\beta$ hydroxybutyrate biosynthesis in the facultative methylotroph Methylobacterium extorquens AM1: identification and mutation of gap11, gap20, and phaR. J Bacteriol 184:6174-6181

Korotkova N, Lidstrom ME, Chistoserdova L (2005) Identification of genes involved in the glyoxylate regeneration cycle in Methylobacterium extorquens AM1, including two new genes, meaC and meaD. J Bacteriol 187:1523-1526

Large PJ, Quayle JR (1963) Microbial growth on $C_{1}$ compounds. 5. Enzyme activities in extracts of Pseudomonas AM1. Biochem J 87:386-396

Large PJ, Peel D, Quayle JR (1961) Microbial growth on $\mathrm{C}_{1}$ compounds. 2. Synthesis of cell constituents by methanol- and formate-grown Pseudomonas AM 1, and methanol-grown Hyphomicrobium vulgare. Biochem J 81:470-480

Large PJ, Peel D, Quayle JR (1962a) Microbial growth on $\mathrm{C}_{1}$ compounds. 3. Distribution of radioactivity in metabolites of methanolgrown Pseudomonas AM1 after incubation with $\left[{ }^{14} \mathrm{C}\right]$ methanol and $\left[{ }^{14} \mathrm{C}\right]$ bicarbonate. Biochem J 82:483-488

Large PJ, Peel D, Quayle JR (1962b) Microbial growth on $\mathrm{C}_{1}$ compounds. 4. Carboxylation of phosphoenolpyruvate in methanolgrown Pseudomonas AM1. Biochem J 85:243-250

Laukel M, Chistoserdova L, Lidstrom ME, Vorholt JA (2003) The tungsten-containing formate dehydrogenase from Methylobacterium extorquens AM1: purification and properties. Eur J Biochem 270: 325-333

Laukel M, Rossignol M, Borderies G, Volker U, Vorholt JA (2004) Comparison of the proteome of Methylobacterium extorquens AM1 grown under methylotrophic and nonmethylotrophic conditions. Proteomics 4:1247-1264

Lee MC, Chou HH, Marx CJ (2009) Asymmetric, bimodal trade-offs during adaptation of Methylobacterium to distinct growth substrates. Evolution 63:2816-2830

Leisinger T, Bader R, Hermann R, Schmid-Appert M, Vuilleumier S (1994) Microbes, enzymes and genes involved in dichloromethane utilization. Biodegradation 5:237-248 
Macauley-Patrick S, Fazenda ML, McNeil B, Harvey LM (2005) Heterologous protein production using the Pichia pastoris expression system. Yeast 22:249-270

Maden BE (2000) Tetrahydrofolate and tetrahydromethanopterin compared: functionally distinct carriers in $\mathrm{C}_{1}$ metabolism. Biochem $\mathrm{J}$ 350(Pt 3):609-629

Martinez-Gomez NC, Nguyen S, Lidstrom ME (2013) Elucidation of the role of the methylene-tetrahydromethanopterin dehydrogenase MtdA in the tetrahydromethanopterin-dependent oxidation pathway in Methylobacterium extorquens AM1. J Bacteriol 195:2359-2367

Marx CJ (2008) Development of a broad-host-range $s a c B$-based vector for unmarked allelic exchange. BMC Res Notes 1:1

Marx CJ, Lidstrom ME (2001) Development of improved versatile broad-host-range vectors for use in methylotrophs and other Gram-negative bacteria. Microbiology 147:2065-2075

Marx CJ, Lidstrom ME (2002) Broad-host-range cre-lox system for antibiotic marker recycling in gram-negative bacteria. Biotechniques 33:1062-1067

Marx CJ, Lidstrom ME (2004) Development of an insertional expression vector system for Methylobacterium extorquens AM1 and generation of null mutants lacking $m t d A$ and/or $f c h$. Microbiology 150:919

Marx CJ, Chistoserdova L, Lidstrom ME (2003a) Formaldehydedetoxifying role of the tetrahydromethanopterin-linked pathway in Methylobacterium extorquens AM1. J Bacteriol 185:7160-7168

Marx CJ, Laukel M, Vorholt JA, Lidstrom ME (2003b) Purification of the formate-tetrahydrofolate ligase from Methylobacterium extorquens AM1 and demonstration of its requirement for methylotrophic growth. J Bacteriol 185:7169-7175

Marx CJ, O'Brien BN, Breezee J, Lidstrom ME (2003c) Novel methylotrophy genes of Methylobacterium extorquens AM1 identified by using transposon mutagenesis including a putative dihydromethanopterin reductase. J Bacteriol 185:669673

Marx CJ, Van Dien SJ, Lidstrom ME (2005) Flux analysis uncovers key role of functional redundancy in formaldehyde metabolism. PLoS Biol 3:e16

Marx CJ, Bringel F, Chistoserdova L, Moulin L, Farhan U1 Haque M, Fleischman DE, Gruffaz C, Jourand P, Knief C, Lee MC, Muller EE, Nadalig T, Peyraud R, Roselli S, Russ L, Goodwin LA, Ivanova N, Kyrpides N, Lajus A, Land ML, Medigue C, Mikhailova N, Nolan M, Woyke T, Stolyar S, Vorholt JA, Vuilleumier S (2012) Complete genome sequences of six strains of the genus Methylobacterium. J Bacteriol 194:4746-4748

McMahon MD, Prather KL (2014) Functional screening and in vitro analysis reveal thioesterases with enhanced substrate specificity profiles that improve short-chain fatty acid production in Escherichia coli. Appl Environ Microbiol 80:1042-1050

Meister M, Saum S, Alber BE, Fuchs G (2005) L-Malyl-coenzyme A/ $\beta$ methylmalyl-coenzyme A lyase is involved in acetate assimilation of the isocitrate lyase-negative bacterium Rhodobacter capsulatus. J Bacteriol 187:1415-1425

Metzger LC, Francez-Charlot A, Vorholt JA (2013) Single-domain response regulator involved in the general stress response of Methylobacterium extorquens. Microbiology 159:1067-1076

Mokhtari-Hosseini ZB, Vasheghani-Farahani E, Shojaosadati SA, Karimzadeh R, Heidarzadeh-Vazifekhoran A (2009) Effect of feed composition on PHB production from methanol by HCDC of Methylobacterium extorquens (DSMZ 1340). J Chem Technol Biotechnol 84:1136-1139

Morris CJ, Lidstrom ME (1992) Cloning of a methanol-inducible moxF promoter and its analysis in moxB mutants of Methylobacterium extorquens AM1rif. J Bacteriol 174:4444-4449

Morris CJ, Biville F, Turlin E, Lee E, Ellermann K, Fan WH, Ramamoorthi R, Springer AL, Lidstrom ME (1994) Isolation, phenotypic characterization, and complementation analysis of mutants of Methylobacterium extorquens AM1 unable to synthesize pyrroloquinoline quinone and sequences of $p q q D, p q q G$, and pqqC. J Bacteriol 176:1746-1755

Morris CJ, Kim YM, Perkins KE, Lidstrom ME (1995) Identification and nucleotide sequences of $m x a A, m x a C, m x a K, m x a L$, and $m x a D$ genes from Methylobacterium extorquens AM1. J Bacteriol 177: $6825-6831$

Muller EE, Hourcade E, Louhichi-Jelail Y, Hammann P, Vuilleumier S, Bringel F (2011) Functional genomics of dichloromethane utilization in Methylobacterium extorquens DM4. Environ Microbiol 13: 2518-2535

Müller JE, Heggeset TMB, Wendisch VF, Vorholt JA, Brautaset T (2014) Methylotrophy in the thermophilic Bacillus methanolicus, basic insights and application for commodity productions from methanol. Appl Microbiol Biotechnol doi:10.1007/s00253-014-6224-3

Nakagawa T, Mitsui R, Tani A, Sasa K, Tashiro S, Iwama T, Hayakawa T, Kawai K (2012) A catalytic role of XoxF1 as $\mathrm{La}^{3+}$-dependent methanol dehydrogenase in Methylobacterium extorquens strain AM1. PLoS One 7:e50480

Nayak DD, Marx CJ (2014a) Genetic and phenotypic comparison of facultative methylotrophy between Methylobacterium extorquens strains PA1 and AM1. PLoS One 9:e107887

Nayak DD, Marx CJ (2014b) Methylamine utilization via the $N$ methylglutamate pathway in Methylobacterium extorquens PA1 involves a novel flow of carbon through $\mathrm{C} 1$ assimilation and dissimilation pathways. J Bacteriol 196:4130-4139

Nunn DN, Lidstrom ME (1986) Isolation and complementation analysis of 10 methanol oxidation mutant classes and identification of the methanol dehydrogenase structural gene of Methylobacterium sp. strain AM1. J Bacteriol 166:581-590

Okubo Y, Skovran E, Guo X, Sivam D, Lidstrom ME (2007) Implementation of microarrays for Methylobacterium extorquens AM1. OMICS 11:325-340

Olah GA (2013) Towards oil independence through renewable methanol chemistry. Angew Chem Int Ed 52:104-107

Orita I, Nishikawa K, Nakamura S, Fukui T (2014) Biosynthesis of polyhydroxyalkanoate copolymers from methanol by Methylobacterium extorquens AM1 and the engineered strains under cobalt-deficient conditions. Appl Microbiol Biotechnol 98:3715-3725

Panda AK (2003) Bioprocessing of therapeutic proteins from the inclusion bodies of Escherichia coli. Adv Biochem Eng Biotechnol 85:43-93

Peel D, Quayle JR (1961) Microbial growth on $\mathrm{C}_{1}$ compounds. 1. Isolation and characterization of Pseudomonas AM 1. Biochem $\mathrm{J}$ $81: 465-469$

Peralta-Yahya PP, Zhang F, del Cardayre SB, Keasling JD (2012) Microbial engineering for the production of advanced biofuels. Nature 488:320-328

Peyraud R, Kiefer P, Christen P, Massou S, Portais JC, Vorholt JA (2009) Demonstration of the ethylmalonyl-CoA pathway by using ${ }^{13} \mathrm{C}$ metabolomics. Proc Natl Acad Sci U S A 106:4846-4851

Peyraud R, Schneider K, Kiefer P, Massou S, Vorholt JA, Portais JC (2011) Genome-scale reconstruction and system level investigation of the metabolic network of Methylobacterium extorquens AM1. BMC Syst Biol 5:189

Peyraud R, Kiefer P, Christen P, Portais JC, Vorholt JA (2012) Coconsumption of methanol and succinate by Methylobacterium extorquens AM1. PLoS One 7:e48271

Pfeifer BA, Khosla C (2001) Biosynthesis of polyketides in heterologous hosts. Microbiol Mol Biol R 65:106-118

Pomper BK, Vorholt JA (2001) Characterization of the formyltransferase from Methylobacterium extorquens AM1. Eur J Biochem 268: 4769-4775

Pomper BK, Vorholt JA, Chistoserdova L, Lidstrom ME, Thauer RK (1999) A methenyl tetrahydromethanopterin cyclohydrolase and a methenyl tetrahydrofolate cyclohydrolase in Methylobacterium extorquens AM1. Eur J Biochem 261:475-480 
Pomper BK, Saurel O, Milon A, Vorholt JA (2002) Generation of formate by the formyltransferase/hydrolase complex (Fhc) from Methylobacterium extorquens AM1. FEBS Lett 523:133-137

Rasche ME, Havemann SA, Rosenzvaig M (2004) Characterization of two methanopterin biosynthesis mutants of Methylobacterium extorquens AM1 by use of a tetrahydromethanopterin bioassay. J Bacteriol 186:1565-1570

Richardson IW, Anthony C (1992) Characterization of mutant forms of the quinoprotein methanol dehydrogenase lacking an essential calcium ion. Biochem J 287(Pt 3):709-715

Roselli S, Nadalig T, Vuilleumier S, Bringel F (2013) The $380 \mathrm{~kb}$ pCMU01 plasmid encodes chloromethane utilization genes and redundant genes for vitamin $\mathrm{B}_{12^{-}}$and tetrahydrofolate-dependent chloromethane metabolism in Methylobacterium extorquens CM4: a proteomic and bioinformatics study. PLoS One 8:e56598

Sanchez S, Demain AL (2008) Metabolic regulation and overproduction of primary metabolites. Microb Biotechnol 1:283-319

Schada von Borzyskowski L, Remus-Emsermann M, Weishaupt R, Vorholt JA, Erb TJ (2014) A set of versatile brick vectors and promoters for the assembly, expression, and integration of synthetic operons in Methylobacterium extorquens AM1 and other Alphaproteobacteria. ACS Synth Biol. doi: 10.1021/sb500221v

Schmidt S, Christen P, Kiefer P, Vorholt JA (2010) Functional investigation of methanol dehydrogenase-like protein $\mathrm{XoxF}$ in Methylobacterium extorquens AM1. Microbiology 156:2575-2586

Schneider K, Peyraud R, Kiefer P, Christen P, Delmotte N, Massou S, Portais JC, Vorholt JA (2012a) The ethylmalonyl-CoA pathway is used in place of the glyoxylate cycle by Methylobacterium extorquens AM1 during growth on acetate. J Biol Chem 287:757766

Schneider K, Skovran E, Vorholt JA (2012b) Oxalyl-coenzyme A reduction to glyoxylate is the preferred route of oxalate assimilation in Methylobacterium extorquens AM1. J Bacteriol 194:3144-3155

Schrader J, Schilling M, Holtmann D, Sell D, Filho MV, Marx A, Vorholt JA (2009) Methanol-based industrial biotechnology: current status and future perspectives of methylotrophic bacteria. Trends Biotechnol 27:107-115

Senior PJ, Windass J (1980) The ICI single cell protein process. Biotechnol Lett 2:205-210

Sirirote P, Yamane T, Shimizu S (1986) Production of L-serine from methanol and glycine by resting cells of a methylotroph under automatically controlled conditions. J Ferment Technol 64:389-396

Sirirote P, Tsuneo Y, Shoichi S (1988) L-serine production from methanol and glycine with an immobilized methylotroph. J Ferment Technol 66:291-297

Skovran E, Crowther GJ, Guo X, Yang S, Lidstrom ME (2010) A systems biology approach uncovers cellular strategies used by Methylobacterium extorquens AM1 during the switch from multito single-carbon growth. PLoS One 5:e14091

Skovran E, Palmer AD, Rountree AM, Good NM, Lidstrom ME (2011) $\mathrm{XoxF}$ is required for expression of methanol dehydrogenase in Methylobacterium extorquens AM1. J Bacteriol 193:6032-6038

Smejkalova H, Erb TJ, Fuchs G (2010) Methanol assimilation in Methylobacterium extorquens AM1: demonstration of all enzymes and their regulation. PLoS One 5:e13001

Sonntag F, Buchhaupt M, Schrader J (2014) Thioesterases for ethylmalonyl-CoA pathway derived dicarboxylic acid production in Methylobacterium extorquens AM1. Appl Microbiol Biotechnol 98(10):4533-4544

Springer AL, Chou HH, Fan WH, Lee E, Lidstrom ME (1995) Methanol oxidation mutants in Methylobacterium extorquens AM1: identification of new genetic complementation groups. Microbiology 141(Pt 11):2985-2993

Springer AL, Morris CJ, Lidstrom ME (1997) Molecular analysis of $m x b D$ and $m x b M$, a putative sensor-regulator pair required for oxidation of methanol in Methylobacterium extorquens AM1. Microbiology 143(Pt 5):1737-1744

Springer AL, Auman AJ, Lidstrom ME (1998) Sequence and characterization of $m x a B$, a response regulator involved in regulation of methanol oxidation, and of mxaW, a methanol-regulated gene in Methylobacterium extorquens AM1. FEMS Microbiol Lett 160: 119-124

Stolz M, Peters-Wendisch P, Etterich H, Gerharz T, Faurie R, Sahm H, Fersterra H, Eggeling L (2007) Reduced folate supply as a key to enhanced L-serine production by Corynebacterium glutamicum. Appl Environ Microbiol 73:750-755

Studer A, Stupperich E, Vuilleumier S, Leisinger T (2001) Chloromethane: tetrahydrofolate methyl transfer by two proteins from Methylobacterium chloromethanicum strain CM4. Eur J Biochem 268:2931-2938

Studer A, McAnulla C, Buchele R, Leisinger T, Vuilleumier S (2002) Chloromethane-induced genes define a third $\mathrm{C}_{1}$ utilization pathway in Methylobacterium chloromethanicum CM4. J Bacteriol 184: 3476-3484

Suzuki T, Yamane T, Shimizu S (1986) Mass production of poly- $\beta$ hydroxybutyric acid by fully automatic fed-batch culture of methylotroph. Appl Microbiol Biotechnol 23:322-329

Sy A, Timmers AC, Knief C, Vorholt JA (2005) Methylotrophic metabolism is advantageous for Methylobacterium extorquens during colonization of Medicago truncatula under competitive conditions. Appl Environ Microbiol 71:7245-7252

Taidi B, Anderson A, Dawes E, Byrom D (1994) Effect of carbon source and concentration on the molecular mass of poly(3hydroxybutyrate) produced by Methylobacterium extorquens and Alcaligenes eutrophus. Appl Microbiol Biotechnol 40:786-790

Tani A, Takai Y, Suzukawa I, Akita M, Murase H, Kimbara K (2012) Practical application of methanol-mediated mutualistic symbiosis between Methylobacterium species and a roof greening moss, Racomitrium japonicum. PLoS One 7:e33800

Thauer RK (1998) Biochemistry of methanogenesis: a tribute to Marjory Stephenson. Microbiology 144(Pt 9):2377-2406

Toyama H, Chistoserdova L, Lidstrom ME (1997) Sequence analysis of $p q q$ genes required for biosynthesis of pyrroloquinoline quinone in Methylobacterium extorquens AM1 and the purification of a biosynthetic intermediate. Microbiology 143(Pt 2): $595-602$

Ueda S, Matsumoto S, Takagi A, Yamane T (1992) Synthesis of poly(3hydroxybutyrate-Co-3-hydroxyvalerate) from methanol and n-amyl alcohol by the methylotrophic bacteria Paracoccus denitrificans and Methylobacterium extorquens. Appl Environ Microbiol 58:3574 3579

Van Aken B, Peres CM, Doty SL, Yoon JM, Schnoor JL (2004) Methylobacterium populi sp. nov., a novel aerobic, pink-pigmented, facultatively methylotrophic, methane-utilizing bacterium isolated from poplar trees (Populus deltoides $\times$ nigra DN34). Int J Syst Evol Microbiol 54:1191-1196

Van Dien SJ, Strovas T, Lidstrom ME (2003) Quantification of central metabolic fluxes in the facultative methylotroph Methylobacterium extorquens AM1 using ${ }^{13} \mathrm{C}$-label tracing and mass spectrometry. Biotechnol Bioeng 84:45-55

Verlinden RA, Hill DJ, Kenward MA, Williams CD, Radecka I (2007) Bacterial synthesis of biodegradable polyhydroxyalkanoates. J Appl Microbiol 102:1437-1449

Vorholt JA (2012) Microbial life in the phyllosphere. Nat Rev Microbiol $10: 828-840$

Vorholt JA, Thauer RK (2002) Molybdenum and tungsten enzymes in C1 metabolism. Met Ions Biol Syst 39:571-619

Vorholt JA, Chistoserdova L, Lidstrom ME, Thauer RK (1998) The NADP-dependent methylene tetrahydromethanopterin dehydrogenase in Methylobacterium extorquens AM1. J Bacteriol 180:53515356 
Vorholt JA, Chistoserdova L, Stolyar SM, Thauer RK, Lidstrom ME (1999) Distribution of tetrahydromethanopterin-dependent enzymes in methylotrophic bacteria and phylogeny of methenyl tetrahydromethanopterin cyclohydrolases. J Bacteriol 181:5750 5757

Vorholt JA, Marx CJ, Lidstrom ME, Thauer RK (2000) Novel formaldehyde-activating enzyme in Methylobacterium extorquens AM1 required for growth on methanol. J Bacteriol 182:6645-6650

Vuilleumier S, Chistoserdova L, Lee MC, Bringel F, Lajus A, Zhou Y, Gourion B, Barbe V, Chang J, Cruveiller S, Dossat C, Gillett W, Gruffaz C, Haugen E, Hourcade E, Levy R, Mangenot S, Muller E, Nadalig T, Pagni M, Penny C, Peyraud R, Robinson DG, Roche D, Rouy Z, Saenampechek C, Salvignol G, Vallenet D, Wu Z, Marx CJ, Vorholt JA, Olson MV, Kaul R, Weissenbach J, Medigue C, Lidstrom ME (2009) Methylobacterium genome sequences: a reference blueprint to investigate microbial metabolism of
C1 compounds from natural and industrial sources. PLoS One 4: e5584

Wilson MC, Moore BS (2012) Beyond ethylmalonyl-CoA: the functional role of crotonyl-CoA carboxylase/reductase homologs in expanding polyketide diversity. Nat Prod Rep 29:72-86

Yang S, Hoggard JC, Lidstrom ME, Synovec RE (2013) Comprehensive discovery of ${ }^{13} \mathrm{C}$ labeled metabolites in the bacterium Methylobacterium extorquens AM1 using gas chromatographymass spectrometry. J Chromatogr A 1317:175-185

Zhang M, Lidstrom ME (2003) Promoters and transcripts for genes involved in methanol oxidation in Methylobacterium extorquens AM1. Microbiology 149:1033-1040

Zhang M, FitzGerald KA, Lidstrom ME (2005) Identification of an upstream regulatory sequence that mediates the transcription of mox genes in Methylobacterium extorquens AM1. Microbiology 151:3723-3728 